\title{
OPEN Advanced removal of Reactive Yellow 84 azo dye using functionalised amorphous calcium carbonates as adsorbent
}

\begin{abstract}
Loredana Brinza ${ }^{1 凶}$, Andreea Elena Maftei ${ }^{1}$, Sorin Tascu ${ }^{2}$, Florin Brinza ${ }^{3}$ \& Mariana Neamtu ${ }^{1 \bowtie}$
Two environmentally friendly organics (ethylenediaminetetraacetic acid, EDTA and its easier biodegradabe isomer, ethylenediamine- $N$, N'-disuccinic acid, EDDS) were used to dope calcium carbonate (CC) nanoparticles intending to increase their adsorptive properties and evaluate adsorption performance (uptake capacity and removal efficiency) for the persistent Reactive Yellow 84 azo dye. Easily synthesized nanomaterials were fully characterized (morphology and size, mineralogy, organic content, surface area, pore size and hydrodynamic diameter). RY84 removal was performed using two consecutive processes: photodegradation after adsorption. The CC-EDTA particles were most efficient for dye removal as compared to the plain and CC-EDDS particles. Adsorption kinetics and isotherms were considered for the CC-EDTA system. 99\% removal occurred via adsorption on $1 \mathrm{~g} / \mathrm{L}$ of adsorbent at $5 \mathrm{mg} / \mathrm{L}$ dye concentration and $\mathrm{pH}$ of 8 and it decreased to $48 \%$ at $60 \mathrm{mg} / \mathrm{L}$. Maximum uptake capacity as described by Langmuir is $39.53 \mathrm{mg} / \mathrm{g}$. As post-adsorption, under UVA irradiation, in the presence of $40 \mathrm{mmol} / \mathrm{L} \mathrm{H}_{2} \mathrm{O}_{2}$, at dye concentration of $10 \mathrm{mg} / \mathrm{L}$ the highest degradation was $49.11 \%$. Substantial decrease of adsorption (ca. 4 times) and photodegradation (ca. 5 times) efficiencies were observed in wastewater effluent as compared to distilled water. The results have important implications to wastewater treatments and appropriate decisions making for the choice of treatment process, process optimization and scaling up to pilot and industrial levels.
\end{abstract}

Nowadays, textile industry received significant attention owing to various type of dyes that often contains highly toxic metal complexes ${ }^{1,2}$. Dyes containing wastewaters are toxic and carcinogenic posing a threat to all living organisms on the trophic chain, including human health ${ }^{3,4}$. In addition, the dyes containing effluents from other industries such as food manufacturing, leather processing, paper industry, printing, paints and cosmetics pose also a critical concern to the environment by contributing to their discharge in fresh waters ${ }^{5,6}$. The most widely and hazardous dyes used in textile industry are azo dyes ${ }^{7}$. They are an aromatic complex compounds being resistant to wastewater handling methods due to their low degradability ${ }^{8}$. Reactive yellow 84 (RY84) is one of reactive textile dye largely used in textile finishing processes ${ }^{9}$. Therefore, their removal form wastewater has a major importance and need to be done before it can be discharged to surface waters.

Different treatment processes such as adsorption, membrane separation, physical and chemical coagulation, advanced oxidation processes (AOP), and biodegradation have been investigated to be applied in wastewater treatment ${ }^{4,10-18}$. The adsorption technology have proved to be the most suitable process in separation and removal of dyes from wastewater due to the economic feasibility and high performance ${ }^{4,10}$. An economic and environmentally feasible adsorbent should possess several important features such as: easily available, non-toxic, reusable, high stability, high selectivity for pollutants of interests, etc. Nanoparticles are promising a greater adsorption capacity due to the large specific surface area, sufficient active pores, inexpensive costs and nontoxicity ${ }^{9}$. Among economic minerals are calcium carbonate (CC) nanoparticles which so far were only tested for fluoride ions removal from aqueous solution ${ }^{19}$. As CC nanoparticles are easily available (one step and rapid synthesis) and green materials (their synthesis uses nontoxic raw materials), its uptake capacity for the removal of a specific azo dye worth to be examined. In addition, the CC nanoparticles have the advantage that they can

\footnotetext{
${ }^{1}$ Department of Exact Sciences and Natural Sciences, Institute of Interdisciplinary Research, Alexandru loan Cuza University of lasi, 11, Carol I Bvd lasi, 700506 lasi, Romania. ${ }^{2}$ Research Center on Advanced Materials and Technologies, Department of Exact and Natural Science, Institute of Interdisciplinary Research, Alexandru Ioan Cuza University of Iasi, 700506 Iasi, Romania. ${ }^{3}$ Faculty of Physics, Alexandru loan Cuza University of Iasi, 700506 lasi, Romania. ${ }^{\boxplus}$ email: Ioredana.brinza@uaic.ro; mariana.neamtu@uaic.ro
} 
be used on a $\mathrm{pH}$ interval (neutral to basic) that is close to the $\mathrm{pH}$ of the dye industrial effluent, thus it does not need major $\mathrm{pH}$ adjustment.

Nowadays, locking for new environmentally friendly and efficient materials for pollutants uptake, the trending is the use of various processes for particles functioning to improve the uptake capacity of pollutants uptake $e^{1,5,9,20,21}$. Accounting on that, this study considers the effect of two nontoxic organic compounds, such as ethylenediaminetetraacetic acid (EDTA) and ethylenediamine-N,N'-disuccinic acid (EDDS) on the CC nanoparticles surface properties, morphology and size, as potential nanoparticles functioning agents. Additionally, their ability to work as (1) scaffolding matrix for the CC structure and (2) potential role as stabilizers of the initial amorphous phase, called amorphous calcium carbonates (ACC), of the final adsorbent material, were also considered as current study hypothesis. The hypotheses that the ACC features a very high surface area as opposed to the ACC transformation end members ${ }^{22-25}$, and that the presence of organics in ACC synthesis may potentially preserve the ACC presence in the final products ${ }^{26-29}$ or will favour the formation of vaterite (higher surface area then calcite) beside calcite and will lead to an increase the surface properties of the final synthesis products, drive our interest in investigating calcium carbonates uptake capacity for an azo dye, named reactive yellow 84 , RY84.

This particular dye poses a special interest due to its low degradability and low uptake on various sorbents which is manly given by its high molecular weight. Thus, the RY84 was chosen to be investigated in this study due to its refractoriness and minimal adsorption studies so far.

Unfortunately, at some industrial sites, depending on the pollutants load and type, some classic methods used could transfer the contaminant from wastewater to solid wastes. Therefore, in these cases other treatments are imposed to be applied for dye removal. Thus, advanced oxidation processes (AOP) are a second choice for dyes removal from wastewater via their total or partial degradation, ideally to invasive compounds such as $\mathrm{CO}_{2}$ and $\mathrm{H}_{2} \mathrm{O}^{30-32}$. AOP using UV irradiation and hydrogen peroxide $\left(\mathrm{UV} / \mathrm{H}_{2} \mathrm{O}_{2}\right)$ give good results in degradation of harmful contaminants and in wastewater treatment ${ }^{17,33-38}$. Therefore, this process could be considerate as a suitable post-treatment process in depollution of effluents from textile dyeing. Beside this, the method also has offered an environmental friendly perspective because it allows process water to be safety discharged with no other secondary products in surface waters or reused back in the industrial process ${ }^{36,39}$.

The textile and finishing industries use large amounts of water and recycling of wastewater could be an opportunity to decrease the cost of water management and could benefit environmental and natural resources. This study presents for the first time the synthesized calcium carbonate nanoparticles in the absence and in the presence of two organic components, applied as adsorbents for dye removal from aqueous solution. Further, studies of RY84 photodegradation post adsorption are carried out to improve its removal. Therefore, this study aims to combine subsequently adsorption and AOP processes $\left(\mathrm{UV} / \mathrm{H}_{2} \mathrm{O}_{2}\right.$ oxidation) for the removal of the most resistant and recalcitrant azo dye, RY84. The objectives of this research are to investigate the optimal conditions for dye removal via both processes.

\section{Results and discussion}

Nanoparticles synthesis and characterization. SEM microscopy. Figure 1 shows the scanning electron microscopic images (SEM) of synthesized carbonates in the presence and the absence of 10\% EDTA and EDDS organics. Figure 1a, displays the spherical nanoparticles with average size of $50 \mathrm{~nm}$. These nanoparticles are very unstable as they were present in solution only few seconds. The image was taken from a sample which was quenched at $30 \mathrm{~s}$ during the synthesis of carbonates without organics. Figure $1 \mathrm{~b}$ displays a vaterite spheric particle of ca 5-8 microns in size, which was the second metastable polymorph intermediate formed in the system during synthesis. Interestingly, vaterite spheres have a rough surface which seems to suggest that they are made of ACC. This observation could be supported by another image captured for the EDTA system (see inset of Fig. 1e) which show a broken empty sphere of vaterite. Figure $1 \mathrm{c}$ and d display the morphology shape and size of the carbonates polymorphs that are formed via an amorphous calcium carbonate and vaterite as metastable intermediates. They are mainly calcite rhombohedral particles of ca 5 microns size with rather neat phases and minor traces of vaterite.

SEM micrographs of calcium carbonates synthetized in the presence of organics show that the addition of EDTA 10\% (Fig. 1e and f) and EDDS 10\% (Fig. 1g and h) led to a change in particles morphology and size. Thus, $10 \%$ organics added to their synthesis seems to have worked as a scaffolding making the calcite surface rougher (more panes and corner), which may have a positive impact on surface properties (i.e., surface area) as adsorbent.

The calcium carbonates possess different morphologies such as calcite, usually found as rhombohedral particles, and vaterite that has a hexagonal structure and here appeared to have a spherical structure and also find in other studies in the literature ${ }^{22,24,40}$. The features of the final products obtained in this study are well defined and consisted spherical shape of vaterite and rhombohedral phase of calcite.

XRD, Raman and FTIR spectroscopies. The experimental XRD spectra obtained in the current study (Fig. 2) match well with the crystal structure of calcite ${ }^{41}$. The strongest $2 \theta$ peak at the value of $29.4^{\circ}$ (Fig. $\left.2 a, b\right)$ represent the main peak of calcite and correspond to the characteristic reflections with d-spacing of $3.036 \AA^{42}$, respectively to the crystallographic plane of $(104)^{43}$. By examining the XRD spectra, it can be observed that the final product has a calcite crystalline structure in both type of environments, with EDTA $10 \%$ and EDDS $10 \%$. The X-ray diffraction pattern with peaks at $2 \theta$ values of $48.45^{\circ}, 48.5^{\circ}$ and $56.48^{\circ}$ corresponding to the d-spacing of $1.887 \AA$, $1.875 \AA$ and $1.631 \AA$ indicate the presence of vaterite, as minor impurity. Similar X-ray lines for synthetic vaterite were identified at $1.858 \AA$ and $1.647 \AA^{42}$. Some differences were observed between the XRD spectra for the carbonates with EDTA 10\% and EDDS 10\%. The spectrum of carbonates with EDDS 10\% (Fig. 2a) has a lower quality, rather broad bands and higher background noise. This could suggest a low degree of crystallinity or a slightly amorphous composition compared to the spectrum of carbonates with EDTA $10 \%$ (Fig. 2b). 
(a)

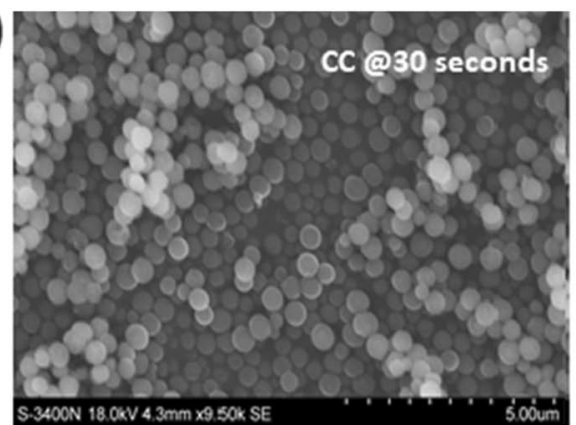

(c)

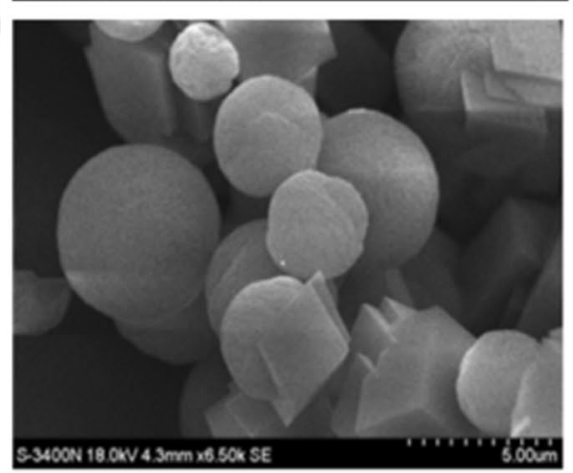

(e)

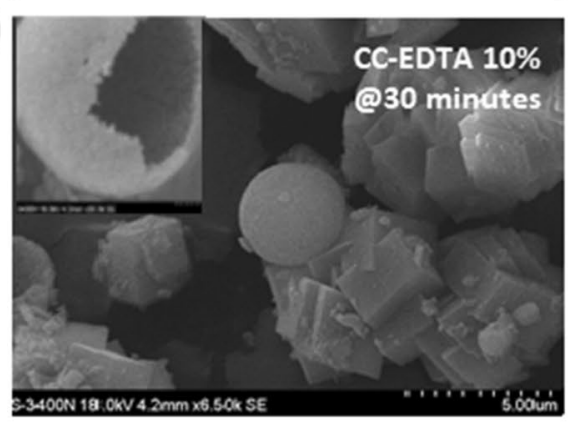

(g)

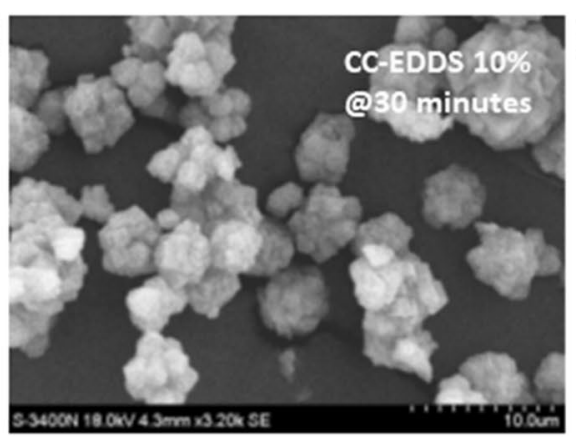

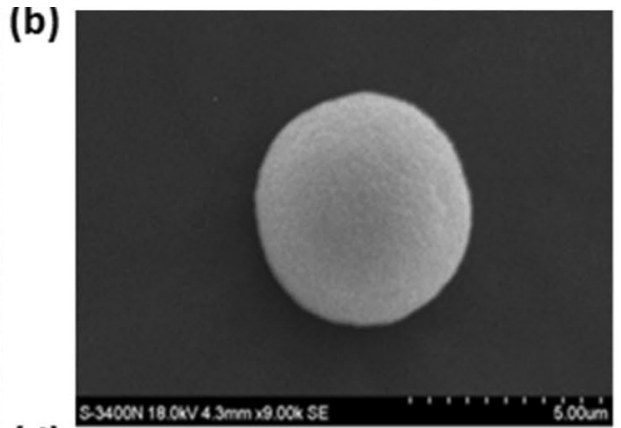

(d)

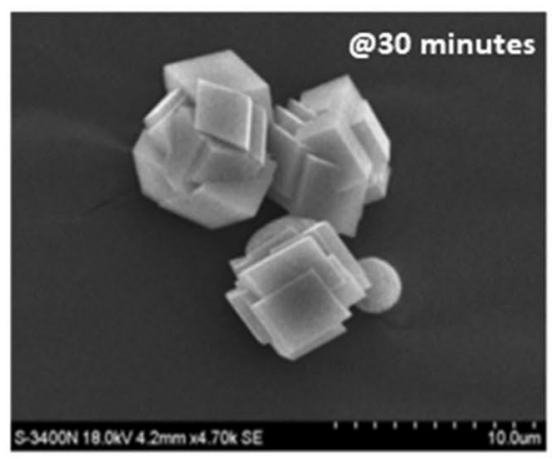

(f)

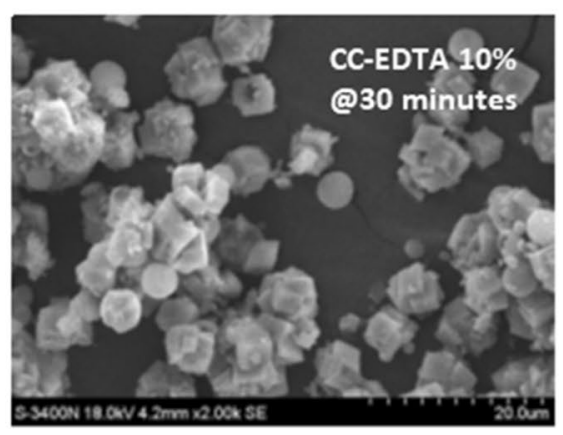

(h)

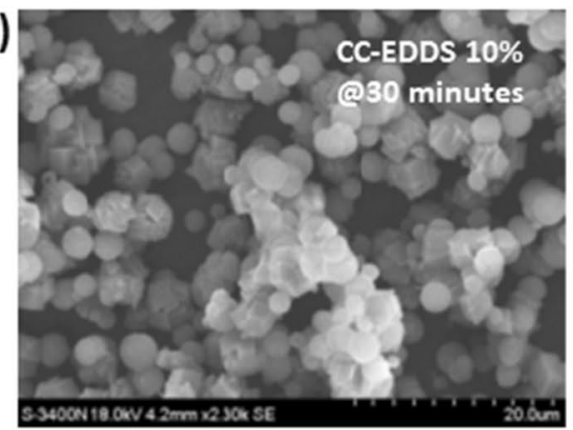

Figure 1. SEM images of carbonates particles synthesis in the absence and in the presence of EDTA $10 \%$ and EDDS 10\%.

The Raman vibrational spectrum of calcium carbonates can be divided in three regions: the vibration of $\left(\mathrm{CO}_{3}\right)^{2-}$ groups (internal modes), which represent the symmetric stretching $v_{1}$ and in plane bending $v_{4}$ of $\mathrm{C}-\mathrm{O}$ bonds, and the region below $400 \mathrm{~cm}^{-1}$ that results from vibration between molecules in the lattice modes or external modes $^{44,45}$. The experimental Raman investigations confirm in this study the presence of calcite and vaterite phases (Fig. $2 \mathrm{c}$ and d), which indicates that the amorphous state of $\mathrm{CaCO}_{3}$ could aggregate first in unstable vaterite before forming the crystalline state of calcite ${ }^{46,47}$. The calcite Raman features are also confirmed in the spectra of samples with $10 \%$ organic addition of EDTA and EDDS, as ACC stabilisers (Fig. 2e and f).

The synthetic calcite structures (Fig. 2c, e, f) showed the characteristic peaks ${ }^{41}$ with small differences between spectra in the absence and in the presence of $10 \%$ organic stabilisers. The most intense signals $v_{1}$ obtained at $1086 \mathrm{~cm}^{-1}$ are assigned to symmetric stretching of $\mathrm{C}-\mathrm{O}$ bonds. These small differences of $v_{1}$ signals obtained and compare with others $v_{1}$ symmetric stretching at $1085 \mathrm{~cm}^{-145,48,49}$ could be caused by the deviation in the lengths of $\mathrm{C}-\mathrm{O}$ bonds in the disordered phase of $\mathrm{ACC}^{44}$. The Raman active lines attributed to $v_{3}$ mode 


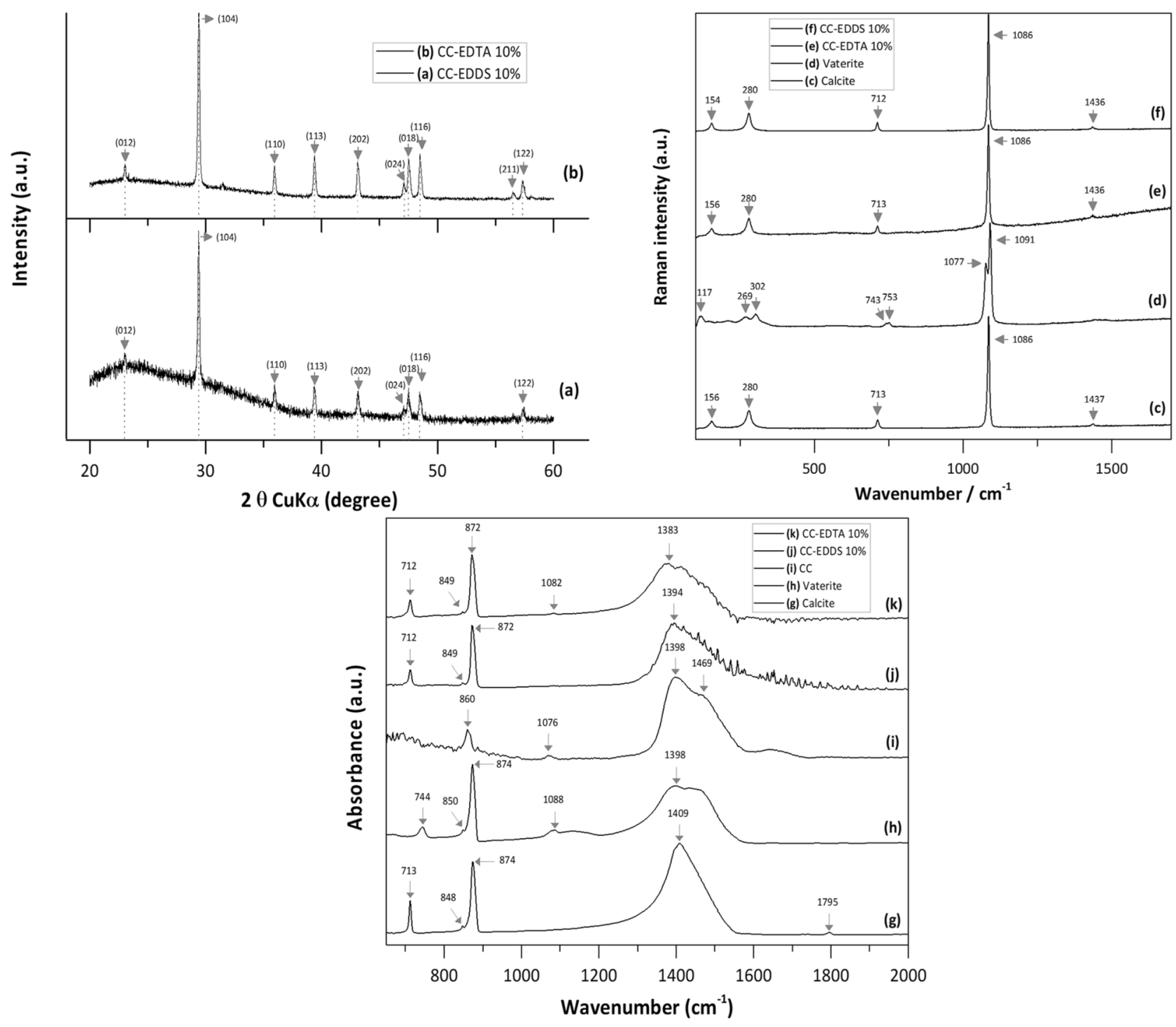

Figure 2. XRD, Raman and FTIR spectra of synthetic calcite.

(antisymmetric stretching) at $1436 \mathrm{~cm}^{-1}$ and $1437 \mathrm{~cm}^{-1}$, respectively are in good agreement with the literature $\mathrm{r}^{48}$. Peaks at $712-713 \mathrm{~cm}^{-1}$ that corresponds to $v_{3}$ mode of C-O in-plane bending, are present in both synthetized products and calcite standard, confirms again the presence of calcite.

The Raman spectrum of vaterite (Fig. 2d) shows typical bands in the region between 1077 and $1091 \mathrm{~cm}^{-1}$ and correspond to the symmetric stretching vibrations $v_{1}^{45,46,49}$ of $\left(\mathrm{CO}_{3}\right)^{2-}$ groups. According to values reported in the literature ${ }^{49}$, the doublet $v_{4}$ in plane bending mode at $743-753 \mathrm{~cm}^{-1}$ it can be shifted to lower or higher wavenumbers. As vaterite is the most unstable $\mathrm{CaCO}_{3}$ polymorph after the ACC, and can be an intermediate precursor phase in calcite crystallization pathway, the presence of these vibrations in the Raman spectrum of the samples with $10 \%$ addition of EDTA, confirm the presence of vaterite phase and provide information about formation mechanism.

FTIR spectroscopy was also used for the characterization of synthetized calcium carbonate phases (Fig. 2g-k). The observed bands $v_{2}$ at $874 \mathrm{~cm}^{-1}$ and $v_{4}$ at $713 \mathrm{~cm}^{-1}$ (Fig. $2 \mathrm{~g}$ ) are characteristic for those reported in literature as featuring calcite ${ }^{24,40,50}$. CC spectrum (Fig. 2i) has a strong $v_{2}$ broad out of plane band at $860 \mathrm{~cm}^{-1}$ and a split peak attributed to $v_{3}\left(\mathrm{CO}_{3}\right)^{2-}$ asymmetric band at $1398 \mathrm{~cm}^{-1}$ and $1469 \mathrm{~cm}^{-1}$. The absence of the $v_{4}$ symmetric vibrations at $713 \mathrm{~cm}^{-1}$ or $744 \mathrm{~cm}^{-1}$ indicate that the calcium carbonate particles are amorphous ${ }^{24,51}$. In the vaterite spectrum (Fig. 2h) the absorption peak at $713 \mathrm{~cm}^{-1}$ is disappeared and a $v_{4}$ deformation band of $\left(\mathrm{CO}_{3}\right)^{2-}$ is located at $744 \mathrm{~cm}^{-140,51,52}$. Apparantly, according to FTIR results, the addition of $10 \%$ organics (Fig. $2 \mathrm{j}$ and $\mathrm{k}$ ) does not have a significant influence in the formation of calcite phase. Besides that, the background noise could suggest an incipient phase in calcite formation. The FTIR spectra obtained are consistent with the observations from XRD and Raman results.

NTA. The nanoparticle tracking analysis (NTA) is a great method able to measure in real-time the particle size, dispersion, changes in the formation and stability of nanoparticles in different solvent systems ${ }^{53}$. 

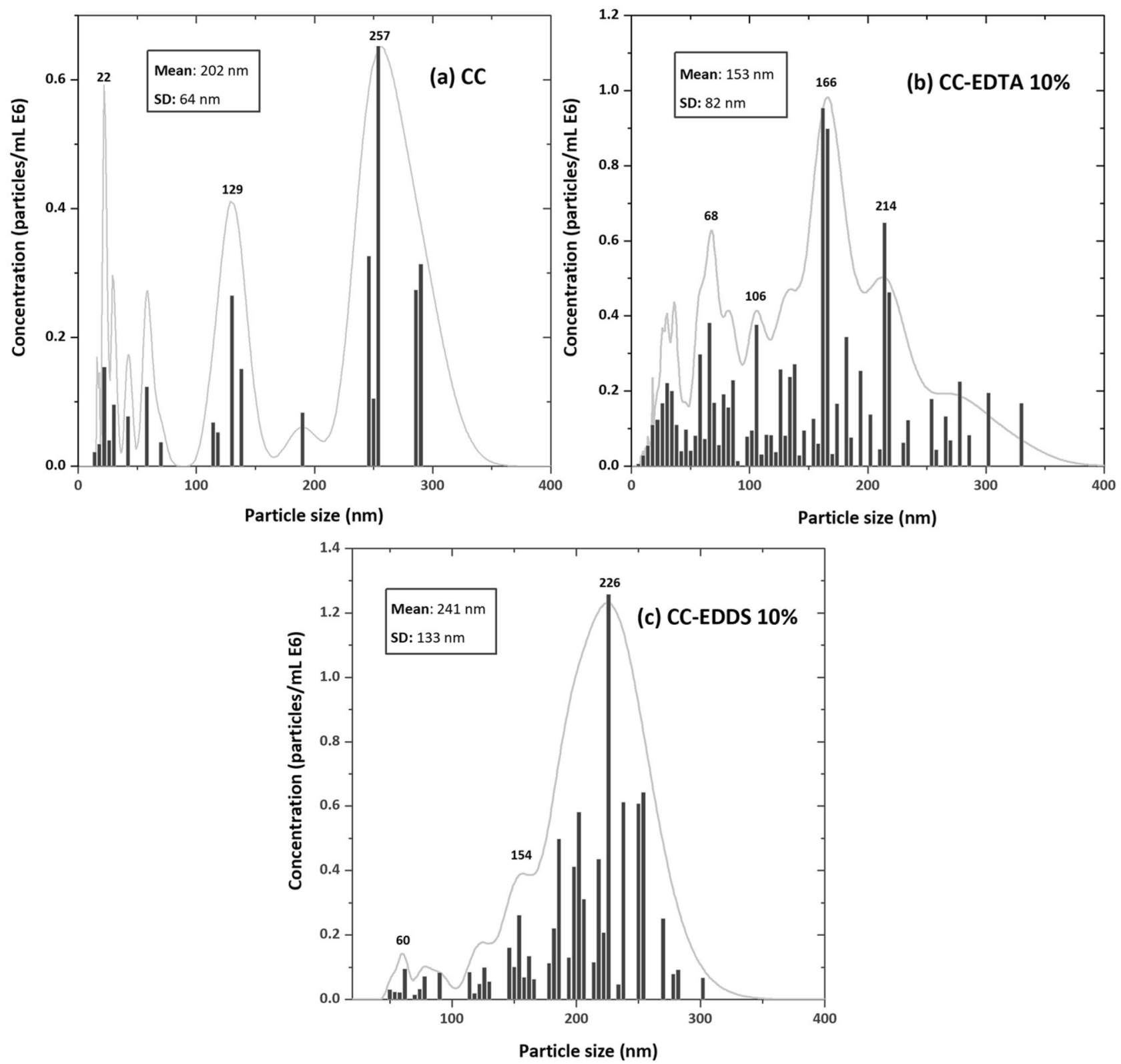

Figure 3. Hydrodynamic size of nanoparticles produced as standard precipitation of: (a) amorphous calcium carbonate (b) carbonates particles synthesis in addition with EDTA 10\%, (c) carbonates particles synthesis in addition with EDDS 10\%.

The obtained hydrodynamic size of nanoparticles characterized by NTA has shown that the particles are grouped in spheroidal clusters sizing between 200 and $300 \mathrm{~nm}$ (Fig. 3). The in situ and real time results from the aggregation in solution experiments show that after the first three seconds the nanoparticles are evidently separated in three individual molecular clusters with an average particle size of ca. $202 \mathrm{~nm}$ (Fig. 3a). From the NTA size distribution profile it can be distinguished three stages: a first stage of crystal nucleation up to $50 \mathrm{~nm}$ (indicative of the formation of amorphous calcium carbonate) that passed progressively through an intermediate stage up to $150 \mathrm{~nm}$ (that can be associated with the formation of vaterite) and a final stage of crystallization (most probably associated with the formation of calcite).

Comparing the results of the three systems, it can be seen that the addition of $10 \%$ organics in the synthesis lead to a decrease in the hydrodynamic size of the final particles for the EDTA system and an increase in the hydrodynamic size of the particles for the EDDS system, partially proving the initial hypotheses of the study (Fig. $3 \mathrm{~b}$ and c), the role of EDTA and EDDS on nanoparticles scaffolding and their effect on surface properties.

BET. Surface area measurements for the CC plain particles gave values of $7.18 \mathrm{~m}^{2} \mathrm{~g}^{-1}$ and $60.3 \mathrm{~m}^{2} \mathrm{~g}^{-1}$ following the BET-Multiple points analysis method (BET-MPM) and the Langmuir method (LM), respectively. Further comparison will be carried out using BET-MPM values, as they are most popular and preferred values presented in the literature ${ }^{54}$. 


\begin{tabular}{|l|l|l|}
\hline Material & Surface area $\left(\mathbf{m}^{2} / \mathbf{g}\right)$ & Pore volume $\mathbf{C C ~}^{-1}$ \\
\hline CC & $\begin{array}{l}\mathrm{MPM}=7.18, \mathrm{R}^{2}=0.997 \\
\mathrm{LM}=60.3\end{array}$ & 0.017 \\
\hline CC-EDTA 10\% & $\begin{array}{l}\mathrm{MPM}=11.16, \mathrm{R}^{2}=0.998 \\
\mathrm{LM}=362.5\end{array}$ & 0.049 \\
\hline CC-EDDS 10\% & $\begin{array}{l}\mathrm{MPM}=2.32, \mathrm{R}^{2}=0.995 \\
\mathrm{LM}=32.3\end{array}$ & 0.0049 \\
\hline
\end{tabular}

Table 1. Summary of BET surface properties of the particles used for adsorption experiments.

The addition of $10 \%$ EDTA led to an increase of the surface area, up to $11.16 \mathrm{~m}^{2} / \mathrm{g}$, whereas the addition of $10 \%$ EDDS led to a substantial decrease (ca. three times smaller) of the surface area, down to $2.32 \mathrm{~m}^{2} / \mathrm{g}$. These differences will have an important impact on adsorption properties such as pollutants uptake capacities and pollutants removal efficiencies.

However, it is to be noted that the BET results (Table 1) are in very good agreement with and respect the same trends as the NTA and the SEM results: smaller particles led to higher surface area.

Overall the BET, NTA and SEM results showed that the addition of EDTA in the synthesis protocol led to better surface properties from adsorption point of view (i.e., smaller particles, rougher surface, and bigger surface area and pore size) for the carbonates particles as opposed to the EDDS. The results show that the EDTA's cis isomer, named EDDS, had an antagonist effect on CC scaffolding compared to the EDTA.

RY84 adsorption onto CC. The effect of $p H$. Experimental adsorption studies were conducted at various $\mathrm{pH}$ values in order to evaluate the optimum uptake $\mathrm{pH}$. The results are presented in Fig. S2. The trend of uptake capacity for the $\mathrm{pH}$ dependent experimental set (run at RT with $\mathrm{C}_{\mathrm{RY} 84} 3 \mathrm{mg} / \mathrm{L}$ and $\mathrm{C}_{\text {ads }}=0.1 \mathrm{~g} / \mathrm{L}$ ) showed an increase from $27.99 \mathrm{mg} / \mathrm{g}$ at $\mathrm{pH} 6$ to maximum of $65.83 \mathrm{mg} / \mathrm{g}$ at $\mathrm{pH} 8$, after which it slightly decreases. The results might be related to the point of zero charge (PZC) of the carbonates and can indirectly provide some information about mechanisms that occurs during the adsorption. The $\mathrm{ZPC}$ for calcite was shown to lie within the range of $\mathrm{pH} 8-9.5^{55,56}$. It is known that surface charge of a solid at the $\mathrm{pH}$ of point of zero charge is null. At $\mathrm{pH}$ below the PZC the calcite surface is positively charged, whereas above it, the surface is negatively charged. As RY84 is a large molecule that contains functional groups that may charge differently in water as a function of $\mathrm{pH}$ : they can become positively charged (protonated, methyl, amino) as well as negatively charged (sulphate, chloride) (see Figs. S1 and S2), heaving a zwitterionic character. This can suggest that theoretically, the RY84 adsorption occurs predominantly between anionic sulphate or chloride ions and protonated surface of carbonates particles at $\mathrm{pH}$ below the $\mathrm{pH}$ of PZC and predominantly between negatively charged surface of carbonates particles and cationic amino and methyl groups of the $\mathrm{RY}$ at the $\mathrm{pH}$ above the $\mathrm{pH}$ of the $\mathrm{PZC}$ as well as potentially at $\mathrm{pH}$ of $\mathrm{PZC}$ via both types of functional groups, however competitively. Similar mechanistic hypotheses that were confirmed to a certain extent by the results were found in literature ${ }^{57,58}$.

As the optimum uptake capacity was found at $\mathrm{pH} 8$ the following experiments were run at this $\mathrm{pH}$.

Adsorption studies onto EDTA/EDDS functionalized CC. The kinetic profiles of the RY84 adsorption onto the three types of particles synthetized and varying the concentration of RY84 are presented in Fig. 4 . The results are expressed as the uptake capacity of the adsorbent (Fig. 4a-e), as well as RY84 removal efficiency from the dye aqueous solution made in distilled water (Fig. $4 \mathrm{f}-\mathrm{j}$ ). First parameter is an expression of the adsorbent ability to load the pollutant under specified experimental conditions and considers adsorbent surface properties (such as surface area, surface charge and particle size), ultimately allowing comparison among the adsorbent's performances. The second parameter, the removal efficiency, features waste quality by expressing the percentage of the pollutant up taken by the applied treatment, here adsorption.

From the kinetic profile of the adsorption it can be seen that the RY84 adsorption occurs relatively fast, the equilibrium is achieved at about 10-20 min, slightly increasing as the RY84 concentration increases. This trend is seen in the uptake capacity kinetic profiles as well as in the RY84 removal efficiency kinetic profiles.

Among the three systems corresponding to each type of the adsorbent used, it can be noticed that at all chosen concentrations the highest performance was achieved by the CC-EDTA $10 \%$ adsorbent followed by the CC and CC-EDDS 10\%, despite of the initial RY84 concentrations used. The uptake capacity of the CC derived particles is ca. two thirds of the CC-EDTA $10 \%$, while CC-EDDS $10 \%$ adsorbent takes up only half of the CCEDTA $10 \%$ adsorbent.

This suggest that the presence of EDTA led to a significant increase of active surface sites available for RY84 binding, while, contrary, the EDDS reduced the surface sites available on the ACC transformation end product particles. These results are in good agreement with the BET measured surface properties of the three transformation products, which indicate a decrease of surface area as follows: CC-EDTA 10\% > CC > CC-EDDS $10 \%$.

Quantitatively Fig. 4a-e shows that the uptake capacity increased with increasing the RY84 concentration reaching the highest values of $28.7 \mathrm{mg} / \mathrm{g}$ for the CC-EDTA $10 \%$ system, $23.00 \mathrm{mg} / \mathrm{g}$ for the CC plain system and $17.34 \mathrm{mg} / \mathrm{g}$ the CC-EDDS $10 \%$ system, in which RY84 initial concentration was set at $60 \mathrm{mg} / \mathrm{L}$. This coherent trend is nicely observed at all chosen concentrations, but it seems not to be linearly proportional with increasing RY84 concentration from concentrations above $10 \mathrm{mg} / \mathrm{L}$, indicating that adsorbents surface may start approach saturation. 

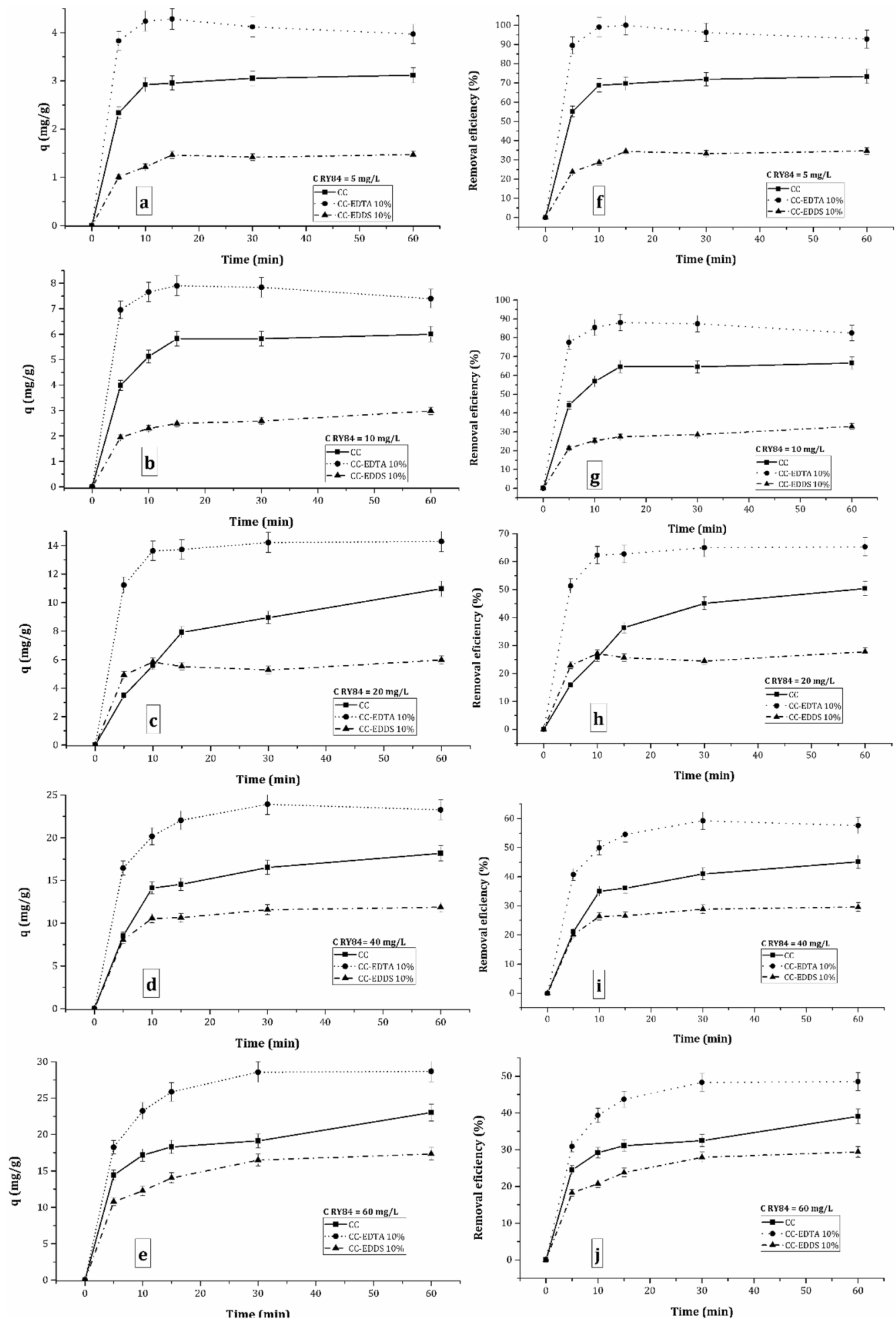

Figure 4. The kinetic profiles of the uptake capacity ( $q$, left) versus removal efficiency (E, right) of RY84 adsorption onto ACC without and with addition of EDDS 10\% and EDTA 10\%. Experimental conditions: $\mathrm{C}_{\mathrm{RY} 84}=5$ to $60 \mathrm{mg} / \mathrm{L}, \mathrm{C}_{\mathrm{ads}} 1 \mathrm{~g} / \mathrm{L}$, batch adsorption at $\mathrm{pH} 8, \mathrm{~T}=\mathrm{RT}$, dynamic regime.

RY84 removal efficiency wise, it is noticed that $100 \%$ RY84 removal occurred at lowest RY84 concentration used, $5 \mathrm{mg} / \mathrm{L}$, and it decreased to $48 \%$ at the highest RY84 concentration used $(60 \mathrm{mg} / \mathrm{L})$ (Fig. $4 \mathrm{f}-\mathrm{j})$. Again, although coherent, this decrease within the concentration interval studied, it was not linearly proportional with 


\begin{tabular}{|c|c|c|c|c|c|c|}
\hline \multirow[b]{2}{*}{ RY84 conc. (mg/L) } & \multicolumn{3}{|c|}{ PFO kinetic model } & \multicolumn{3}{|c|}{ PSO kinetic model } \\
\hline & q (mg/g) & $k_{1}\left(\min ^{-1}\right)$ & Aj. $R^{2}$ & $\mathrm{q}(\mathrm{mg} / \mathrm{g})$ & $k_{2}\left(g g^{-1} \min ^{-1}\right)$ & Aj. $R^{2}$ \\
\hline 5 & $4.154 \pm 0.065$ & $0.521 \pm 0.093$ & 0.994 & $4.184 \pm 0.06$ & $0.838^{\star}$ & 0.991 \\
\hline 10 & $7.713 \pm 0.102$ & $0.465 \pm 0.059$ & 0.996 & $7.852 \pm 0.11$ & $0.256^{*}$ & 0.993 \\
\hline 20 & $14.141 \pm 0.099$ & $0.315 \pm 0.013$ & 0.999 & $14.924 \pm 0.316$ & $0.046 \pm 0.009$ & 0.995 \\
\hline 40 & $23.250 \pm 0.391$ & $0.229 \pm 0.017$ & 0.995 & $25.135 \pm 0.5881$ & $0.016 \pm 0.002$ & 0.995 \\
\hline 60 & $28.261 \pm 0.515$ & $0.189 \pm 0.014$ & 0.995 & $31.081 \pm 0.556$ & $0.009 \pm 0.001$ & \begin{tabular}{|l|}
0.997 \\
\end{tabular} \\
\hline
\end{tabular}

Table 2. Summary of the PFO and PSO kinetic modelling parameters for the CC-EDTA $10 \%$ system. Experimental conditions: $\mathrm{C}_{\mathrm{RY} 84}=5-60 \mathrm{mg} / \mathrm{L}$, batch adsorption at $\mathrm{pH} 8, \mathrm{~T}=\mathrm{RT}, \mathrm{C}_{\text {ads }} 1 \mathrm{~g} / \mathrm{L}$.

increasing concentration. These results suggest that for a contaminated water containing $5 \mathrm{mg} / \mathrm{L} \mathrm{RY} 84$ an adsorbent dosage of $1 \mathrm{~g} / \mathrm{L}$ is sufficient to ensure an efficient wastewater treatment, whereas for higher concentrations of RY84 in polluted wastewaters, the CC-EDTA $10 \%$ dosage should be adjusted in a non-linear proportional manner.

Although the kinetic profiles showed that the adsorption equilibrium has been reached in all systems, the conclusion that the surface saturation was reached in all systems it cannot be made. This can be seen by comparing $\mathrm{q}$ with E profiles at each working concentration. Thus, as example, focusing on the data from the experiment run at the middle concentration chosen, i. e., $20 \mathrm{mg} / \mathrm{L}$, for the CC- EDTA $10 \%$ system (see Fig. $4 \mathrm{c}$ and $\mathrm{h}$ ), the addition of $1 \mathrm{~g} / \mathrm{L}$ adsorbent led to a maximum adsorbent load $14.2 \mathrm{mg} / \mathrm{g}$ that ensured an $65 \%$ efficiency of RY84 removal from solution. Further, by increasing RY84 concentration (to $40 \mathrm{mg} / \mathrm{L}$, Fig. $4 \mathrm{~d}$ and/or $60 \mathrm{mg} / \mathrm{L}$, Fig. 4e) the adsorbent load increases (to $23.5 \mathrm{mg} / \mathrm{g}$ and $28.7 \mathrm{mg} / \mathrm{g}$, respectively), suggesting that the adsorbent has still potential to uptake more RY84. Thus, those $35 \%$ of RY 84 from solution at $20 \mathrm{mg} / \mathrm{L}$ could have been very well up taken. Moreover, by looking at $\mathrm{q}$ and $\mathrm{E}$ profiles for system at higher RY84 concentrations, it seems that the adsorbent did not reach the saturation under conditions above $20 \mathrm{mg} / \mathrm{L}$, and that there are still RY84 molecules in solution to be up taken: ca. $45 \%$ and $55 \%$ for the 40 and $60 \mathrm{mg} / \mathrm{L}$ systems, respectively (the efficiency of RY 84 removal being ca. 55\% and $45 \%$ for the 40 and $60 \mathrm{mg} / \mathrm{L}$ systems, respectively). On another hand, a decrease of removal efficiency with the increasing RY84 concentration in solution that concomitantly led to an increase of adsorbent load may suggest that the RY84 binding is limited to only specific surface sites.

From the above interpretation of the results, it can be concluded that the adsorption is a complex interplay of mechanisms that occurs simultaneously to a specific extent. It is limitative not only by RY84 concentration or adsorbent dosage, surface charge/surface area, sites densities and their type but also the molecule size of RY84 that may only bind specifically at physically accessible sites.

Overall, from process engineering point of view, it is useful to display the results as $\mathrm{q}$ as well as E, as they provide important information about sorption mechanism as well as help process engineers dose the appropriate amounts of adsorbent to achieve targeted removal efficiencies.

As best quantitative results, among the three adsorbents chosen for the adsorption, were given by the CC doped with EDTA 10\%, only these nanoparticles will be further treated for the kinetic and isothermal modelling and photodegradation studies.

Kinetic modelling. Adsorption kinetic modelling fits for the CC doped with EDTA 10\% system are presented in Table 2. The kinetic modelling allowed the determination of weighted values for uptake capacities (at equilibrium, under specific experimental conditions that are mentioned in the table) as well as derive adsorption rates for each individual system. Fitted q values, that provides quantitative information about the RY84 uptake capacity at equilibrium can further be used in literature comparisons with other sorbents or other pollutants, but only if experimental conditions ( $\mathrm{pH}$, solid to liquid or pollutant to solid ratios, temperature), are similar. The goodness of fit is appreciated function of the highest value of adjusted regression coefficient-adjusted $\mathrm{R}^{259-62}$. Considering the assumptions of each kinetic model are based to, a better fit to one of the models chosen provides indirect and empirical information about adsorption mechanism. Thus, generally a better fit to the PFO kinetic model implies that the adsorption mechanism occurs preponderantly via physical sorption, while a better fit to the PSO kinetic model implies a chemical sorption mechanism.

Modelling the adsorption experimental data for the set of the experiments, in which the RY84 concentration was varied from 5 to $60 \mathrm{mg} / \mathrm{L}$, with the pseudo first order and pseudo second kinetic models, the following coherent trends regarding the weighted values of $\mathrm{q}$ and reaction rates were observed: the uptake capacity increases coherently (from ca. 4.154 to $28.261 \mathrm{mg} / \mathrm{g}$ ) with the increase of RY84 concentration (from 5 to $60 \mathrm{mg} / \mathrm{L}$ ) and the adsorption rate values decrease with increasing concentration (Fig. S3). These coherent trends visible on both models fits suggest that the adsorption occurs slower as RY84 concentration increases.

Looking at the regression coefficient, it can be noticed that the $\mathrm{R}^{2}$ values obtained for the PFO and the PSO are close to unit, slightly differing at the third decimal (Table 2). This fact suggests that, generally, adsorption take place via physical and chemical sorption mechanisms, interplaying to a specific extent as function of RY84 concentration. However, a closer look showed that at low RY84 concentrations (up to $20 \mathrm{mg} / \mathrm{L}$ ) the data are slightly better fitted by the PFO kinetic model as opposed to the PSO model, suggestion that in these systems the adsorption mechanism is preponderantly physical sorption (occurring via $\mathrm{H}$ or Van der Walls bonding).

At RY84 concentration of $40 \mathrm{mg} / \mathrm{L}$, the modelling fits returned an identic regression coefficient, fact that suggest that both mechanism, physical and chemical sorption occurs equally in the same system. Interestingly, this 


\begin{tabular}{|l|l|l|}
\hline & Langmuir isotherm & Freundlich isotherm \\
\hline Parameters & $\begin{array}{l}\mathrm{q}_{\max }=39.52 \pm 2.94 \mathrm{mg} \mathrm{g}^{-1} \\
\mathrm{~b}=0.08 \pm 0.02 \\
\mathrm{R}_{\mathrm{L}}=0.076-0.760\end{array}$ & $\begin{array}{l}\mathrm{K}_{\mathrm{f}}=6.685 \pm 1.31 \mathrm{mg} \mathrm{g}^{-1} \\
1 / \mathrm{n}=0.301 \pm 0.03\end{array}$ \\
\hline Statistics & $\begin{array}{l}\text { Adj. } \mathrm{R}^{2}=0.961 \\
\text { Red. } \mathrm{X}^{2}=6.4562\end{array}$ & $\begin{array}{l}\text { Adj. } \mathrm{R}^{2}=0.956 \\
\text { Red. } \mathrm{X}^{2}=7.568\end{array}$ \\
\hline
\end{tabular}

Table 3. Summary of fitting parameters from adsorption isotherms modelling with the Langmuir and Freundlich models. Experimental conditions: $\mathrm{C}_{\mathrm{RY} 84}=5-200 \mathrm{mg} / \mathrm{L}$, batch adsorption at $\mathrm{pH} 8, \mathrm{~T}=\mathrm{RT}, \mathrm{C}_{\mathrm{ads}} 1 \mathrm{~g} / \mathrm{L}$.

concentration seems to be the limit at which a slight change in the proportionality of the mechanisms change, by taking over a preponderantly chemisorption mechanism (that occurs via strong chemical bonding, i.e., covalent and coordination bonding).

Adsorption isotherms. The experimental data from experiments were RY84 concentration was varied (5-200 mg/L), but sorbent dosage was kept constant $(1 \mathrm{~g} / \mathrm{L})$, led to plots of the adsorption isotherms. The data were fitted with the most common adsorption models such as Langmuir and Freundlich and their fits are displayed in Fig. S4 with the summary of the fitting parameter presented in Table 3. Both models are theoretical and/or empirical expression of adsorption equilibrium, and they involve various assumptions used to derive indirect mechanistic information. Moreover, they can be used to obtain and compare maximum adsorption capacities of various adsorbents for specific adsorbents or of various adsorbents for the same adsorbent, under similar or ideally identical process conditions ${ }^{63-65}$.

The modelling yielded a slightly better fit to the Langmuir isotherm (Adj. $R^{2}=0.961$ ) compared to the Freunlich isotherm (Adj. $\mathrm{R}^{2}=0.956$ ) (Table 3 and Fig. S4). The best fit to the Langmuir model indirectly suggests that the adsorption may occur as a monolayer with a maximum up take capacity of $39.52 \mathrm{mg} / \mathrm{g}$. The positive RL parameter, calculated from Langmuir parameters indicated that adsorption is favourable.

From the adsorbent point of view, the adsorption optimal experimental conditions for the CC-EDTA $10 \%$ adsorbent are: max uptake capacity of $39.53 \mathrm{mg} / \mathrm{g}$ at $\mathrm{pH} 8$, room temperature, dynamic regime and dye concentration of $60 \mathrm{ml} / \mathrm{L}$. Efficiency wise, the optimal experimental conditions obtained are: $100 \%$ removal at $1 \mathrm{~g} / \mathrm{L}$ adsorbent dosage and dye concentration of $5 \mathrm{mg}$.L under stirring condition at room temperature and $\mathrm{pH} 8$.

The maximum uptake capacity obtained from isothermal fits allow comparison of the CC-EDTA10\% performance with other adsorbents found in literature and used for RY84 uptake as well as helps process engineer guide for dosing the correct amount of sorbent into a specific wastewater system to ensure the targeted level of dye removal.

Presented results showed that the addition of EDTA provided superior uptake capacity for the CC as adsorbent as opposed to EDDS. There are no many adsorption studies on RY84 in literature. Similar RY dyes adsorbed onto a variety of bio and geo, natural and synthetic absorbents were found (Table S3). Thus, a sensible comparison is limited by the lack of adsorption studies for the RY84 azo dye. However, accounting on El Haddad et al., $(2012)^{66}$, Barka et al., (2011) ${ }^{67}$ and Abdolmohammad-Zadeh et al. ${ }^{68}$ works on RY84 adsorption onto animal bone meal, hydroxyapatite and nano $\mathrm{Zn}$-Al layered double hydroxide, respectively the maximum uptake capacity was compared (Table S3). The CC-EDTA 10\% has very good uptake capacity for RY84 (39.53 mg/g) compared to other sorbents tested in the literature such as: hydroxyapatite $(48.84 \mathrm{mg} / \mathrm{g})^{67}$, nano $\mathrm{Zn}$-Al layered double hydroxide $(13.75 \mathrm{mg} / \mathrm{g})^{68}$ and animal bone $(57.15 \mathrm{mg} / \mathrm{g})^{66}$ (see Table S3). Outstanding uptake capacities for RY84 were found for functionalised chitosan based adsorbents at $\mathrm{pH} 3-4$. The authors have found maximum q values, of $2234.3 \mathrm{mg} / \mathrm{g}, 2000.1 \mathrm{mg} / \mathrm{g}$ and $1774.2 \mathrm{mg} / \mathrm{g}$ for RY84 onto chitosan with epichlorohydrin, ECH-CHs, chitosan with glutaraldehyde, ALD-CHs and Chitosan, $\mathrm{CHs}$, respectively ${ }^{69}$. However, despite their great performance the adsorbents are made using compounds with a high degree of toxicity (epichlorohydrin is classified by several international health research agencies and groups as a probable or likely carcinogen in humans (stomach and lungs); glutaraldehyde is toxic and a strong irritant with potential high risk for cancerous). Thus, their use and final disposal post adsorption may pose environmental concerns due to their toxicity.

Differences of our results compared to the literature findings may be explained by differences in $\mathrm{pH}$ as well as adsorbent surface properties. Generally, the adsorption capacity strongly depends on adsorption surface properties (surface charge properties, size, surface area, pore presence and size, sites densities, the concentration of acidic/ wick acidic, basic functional groups etc.), sorbent stability under specific conditions (i.e. $\mathrm{pH}$ ). $\mathrm{pH}$ influences the surface chemistry as well as pollutant chemistry in solution beside process controlled parameters such as mixing type and speed, rheology, temperature etc.). It is also observable that RY84 possesses a high molecular weight $(1922.45 \mathrm{~g} / \mathrm{mol}$ ) as compared to other RY dyes (Fig. S1 and Table S3). On specific adsorbents surfaces it is possible that due to molecule size, its adsorption at adsorbent sites to be physically limited and thus led to a lower uptake capacity.

Thus, the necessity of coupling the adsorption process with the photodegradation process may rise in order to improve the RY84 removal efficiency at sites where its concentration in industrial effluents are elevated.

UVA-induced photodegradation studies. The photodegradation process was investigated using the supernatant from the most efficient adsorbent, CC-EDTA 10\%, under UVA irradiation. The initial concentration of RY84 solutions was set from 10 to $40 \mathrm{mg} / \mathrm{L}$. It is notable that, when exposed to UVA light in absence of $\mathrm{H}_{2} \mathrm{O}_{2}$, a small conversion was observed (up to $14 \%$, Table S4). In the presence of both $\mathrm{H}_{2} \mathrm{O}_{2}$ and UVA light the conver- 

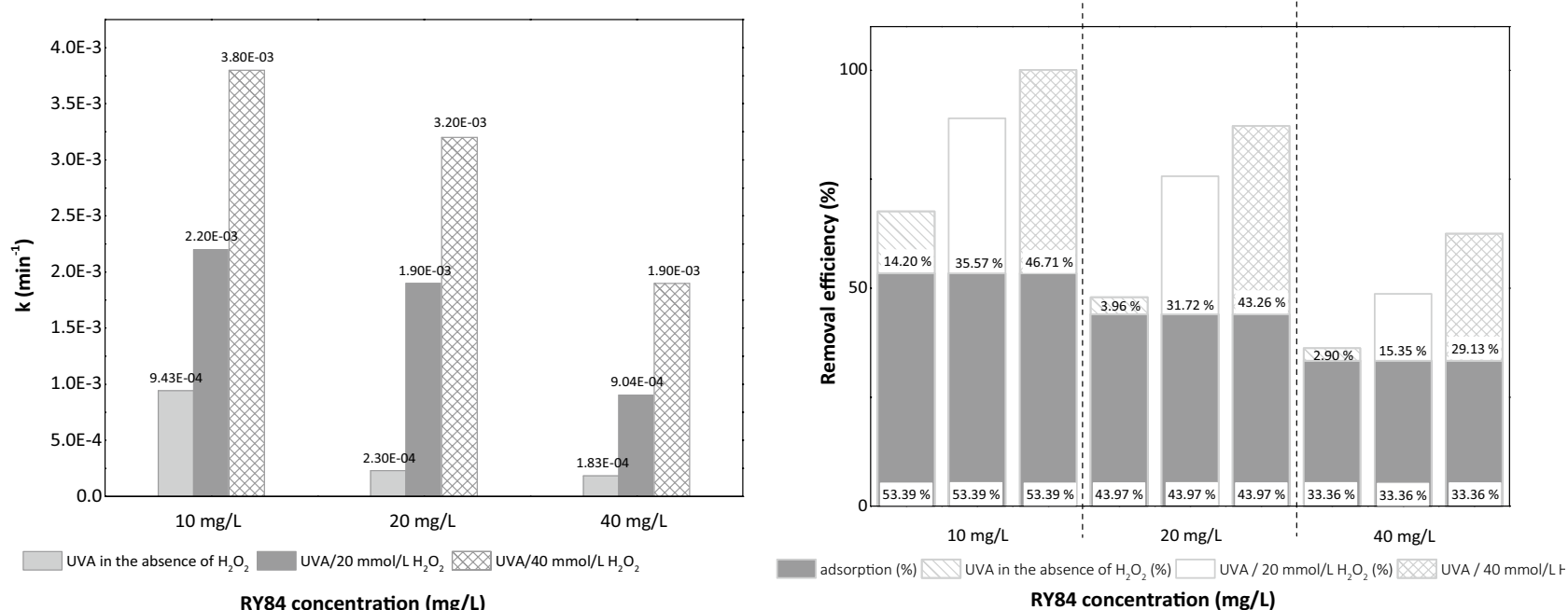

RY84 concentration $(\mathrm{mg} / \mathrm{L})$

RY84 concentration (mg/L)

Figure 5. (a) Photodegradation rate constant $\left(\mathrm{k}, \mathrm{min}^{-1}\right)$ of $\mathrm{RY} 84$ after adsorption using CC-EDTA $10 \%$ nanoparticles $(1 \mathrm{mg} / \mathrm{L})$ at different concentrations in the absence and presence of $\mathrm{H}_{2} \mathrm{O}_{2}$. (b) Total removal of $\mathrm{RY} 84$ via consecutive adsorption and UVA/ $\mathrm{H}_{2} \mathrm{O}_{2}$ processes. Experimental conditions: $\mathrm{pH} 7.3 \mathrm{RT}$, adsorption time $60 \mathrm{~min}$ (dynamic regime), photodegradation time $180 \mathrm{~min}$ (static regime), $\mathrm{R}^{2}$ is between 0.98 and 0.99 .

sion increased substantially due to the hydroxyl radicals generated during the photochemical reactions. After $60 \mathrm{~min}$ of irradiation the removal of $10 \mathrm{mg} / \mathrm{L} \mathrm{RY} 84$ were only $5 \%$ and $24 \%$ in absence and presence of $\mathrm{H}_{2} \mathrm{O}_{2}$, respectively. After $180 \mathrm{~min}$ of irradiation the removal increased to $14 \%$ and $49 \%$ in absence and presence of $\mathrm{H}_{2} \mathrm{O}_{2}$, respectively, whereas only $2.90 \%$ and $29 \%$ of $40 \mathrm{mg} / \mathrm{L}$ RY84 were removed, respectively. The corresponding (pseudo) first order constants were $9.43 \times 10^{-4} \mathrm{~min}^{-1}$ for $10 \mathrm{mg} / \mathrm{L} \mathrm{RY} 84$ in absence of hydrogen peroxide and $3.8 \times 10^{-3} \mathrm{~min}^{-1}$ in presence of $\mathrm{H}_{2} \mathrm{O}_{2}$ (Fig. 5a). The photodegradation rate constant increased as the initial concentration of RY84 is decreased. The lower removal of RY84 degradation at higher initial concentration of dye is probably due to absorption of light at $365 \mathrm{~nm}$ and competition for hydroxyl radicals by compound. The same inhibiting tendency was observed for degradation of different pollutants ${ }^{70-72}$. The pseudo first order constant in the presence of $\mathrm{H}_{2} \mathrm{O}_{2}\left(3.8 \times 10^{-3} \mathrm{~min}^{-1}\right)$ for the removal of $10 \mathrm{mg} / \mathrm{L} \mathrm{RY84}$ is over four times greater than that with no $\mathrm{H}_{2} \mathrm{O}_{2}$ (Fig. 5a). From practical point of view this means that the volume of the photoreactor for the same flow rate of water can be over four times smaller.

Removal of RY84 from wastewater effluent by adsorption and photodegradation processes. The experimental results obtained from testing the uptake capacity of CC-EDTA 10\% for RY 84 removal from real wastewater are presented in Fig. 6. A comparison of the adsorption results obtained from the experiments run in distilled water vs. wastewater at the same RY84 concentration (10 mg/L, Fig. 4), show that the adsorption occurred fast but with substantial decrease (ca 4 times) of the adsorption capacity (from ca. 7.7 to $1.8 \mathrm{mg} / \mathrm{g}$ ) as well as RY84 removal efficiency (from 88 to $18 \%$ ).

The decrease can be explained by competitive effect of other ions present in the wastewater background that bind preferentially at adsorbent surface sites and led to ca. $75 \%$ occupancy of the surface sites. This output, is essential for industrial process designing as it can guide the process engineer to consider significant adjustments in the adsorption dosage during the adsorption process, to reach the targeted efficiency of the RY 84 removal. Thus, we performed the removal of RY84 using two consecutive processes: photodegradation after adsorption to obtain simulations of removal processes that might be used during water treatment in textile industry.

The efficiency of the RY84 photodegradation in wastewater in the presence of 20 and $40 \mathrm{mmol} / \mathrm{L}_{\text {of }} \mathrm{H}_{2} \mathrm{O}_{2}$ decreased (ca. five times) compared to the degradation efficiency in the distilled water (from 35.57 to $7.65 \%$ and from 49.11 to $32.11 \%$, respectively) (Figs. $5 \mathrm{~b}$ and $7 \mathrm{~b}$ ). The photodegradation of RY84 in wastewater effluent was slower $\left(\mathrm{k}=4.8 \times 10^{-4} \mathrm{~min}^{-1}\right)$ than in the experiments with dissolved natural organic matter (DNOM)-free water (MilliQ water) $\left(\mathrm{k}=9.43 \times 10^{-4} \mathrm{~min}^{-1}\right)$ (Fig. $7 \mathrm{a}$ and Table S5).

This can be explained by the effect of common wastewater constituents such as $\mathrm{HCO}_{3}{ }^{-}, \mathrm{NO}_{3}{ }^{-}$, total suspended matter and Fe (III) ions on photodegradation of RY84, probably due to absorption of light and competition for hydroxyl radicals by existing scavengers in water (humic-like substances). It is generally accepted that DNOM effects the degradation of pollutants dissolved in water through various reactions. In most cases, the natural organic matter quenches the excited state of the pollutant. Our results are in agreement with the data reported by Rueda-Marquez ${ }^{73}$, who found that the removal of organic pollutants strongly decreases in the presence of complex real wastewaters.

Overall, the current results have important implications to wastewater treatments in textile industry and appropriate decisions making, from many respects, including: (1) the choice of treatment process, (2) wastewater treatment design, (3) control and monitoring of the processes from the point of view of process engineering, as well as (4) further process optimization and scaling up to pilot and industrial levels. Coupling the two processes in wastewater treatments can be a feasible alternative at sites where the concentration of refractive reactive dyes 


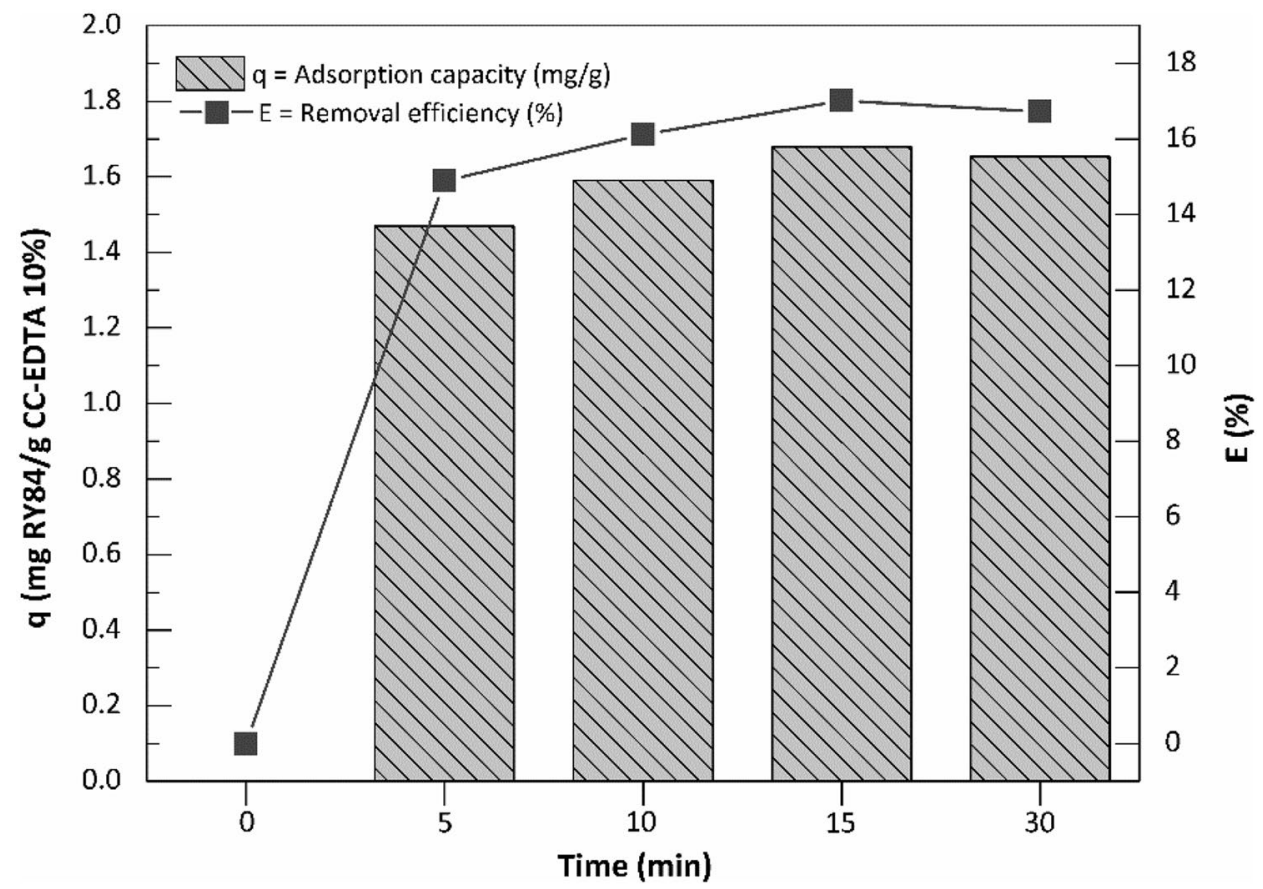

Figure 6. The kinetic profiles of the uptake capacity versus removal efficiency of RY84 adsorption onto CC-EDTA $10 \%$ in wastewater.

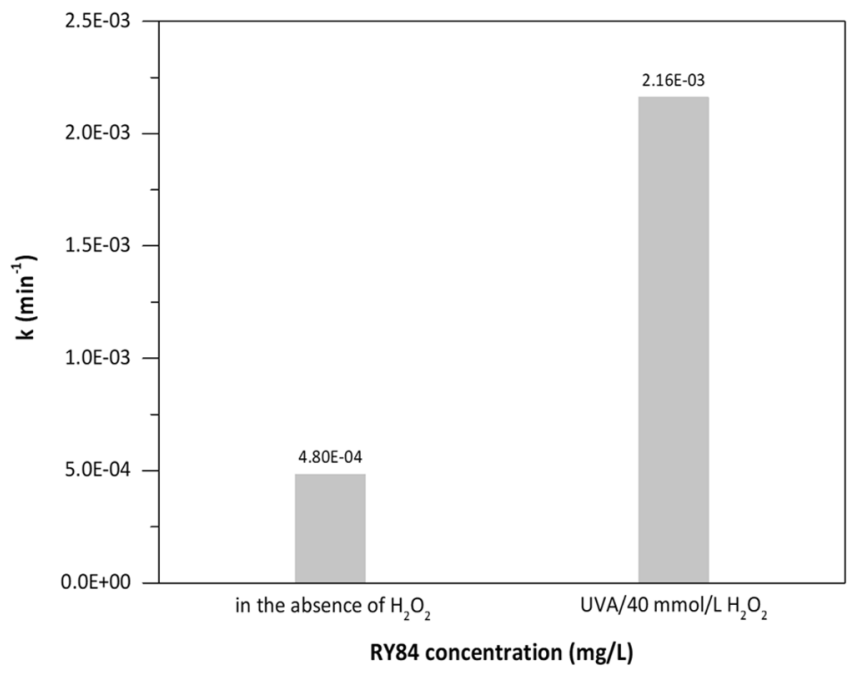

(a)

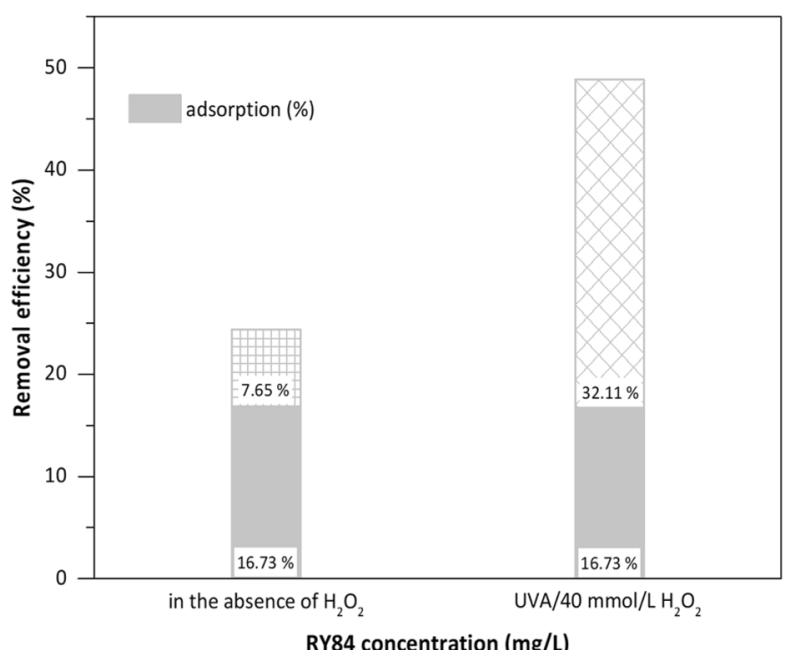

(b)

Figure 7. (a) Photodegradation rate constant $\left(\mathrm{k}, \mathrm{min}^{-1}\right)$ of RY84 after adsorption using CC-EDTA $10 \%$ nanoparticles $(1 \mathrm{mg} / \mathrm{L})$ in the absence and presence of $\mathrm{H}_{2} \mathrm{O}_{2}$. (b) Total removal of RY84 in wastewater effluent by adsorption and photodegradation processes. Experimental conditions: pH 7.3 RT, adsorption time $60 \mathrm{~min}$ (dynamic regime), photodegradation time $180 \mathrm{~min}$ (static regime).

in wastewater is high and where only one of the removal processes would prove to be an insufficient. Although the photodegradation has the advantage that it totally or partially degrade the RY84, for large molecules this process is relatively slow, thus an adsorption step could be used prior photodegradation to minimise the content of dye. On the other hand, the adsorption process has the advantage that concentrate most of the dye fast on an environmentally friendly sorbent, that can be regenerated by thermal treatments and reuse in multiple cycles $^{74}$. This will make the subject of further research. 


\section{Methods}

Materials. Pure grade chemicals such as $\mathrm{CaCl}_{2}$ (CAS: 10043-52-4), $\mathrm{Na}_{2} \mathrm{CO}_{3}$ (CAS: 497-19-8), $\mathrm{NaOH}$ (CAS: 1310-73-2), HCl (CAS: 7647-01-0), EDTA (CAS: 139-33-3), EDDS (CAS) (Fig. S1) and distilled deionized water were used for materials synthesis. These analytical high purity reagents were purchased from Sigma Aldrich. The adsorption proprieties were investigated by using Reactive Yellow 84 (RY84) as model dye.

Experimental setup. The synthesis experiments were carried out by mixing equal volumes of equal concentrations of $100 \mathrm{mmol} / \mathrm{L} \mathrm{Na}_{2} \mathrm{CO}_{3}$ and $100 \mathrm{mmol} / \mathrm{L} \mathrm{CaCl}_{2}$ under rigorous stirring. The addition of $10 \%$ EDTA and EDDS was made in $\mathrm{Na}_{2} \mathrm{CO}_{3}$ solution before mixing with the $\mathrm{CaCl}_{2}$ solution. The $\mathrm{pH}$ was checked and adjusted when needed to a constant value of 11.2 with $2 \mathrm{~mol} / \mathrm{L} \mathrm{NaOH}$ or $10 \mathrm{mmol} / \mathrm{L} \mathrm{HCl}$.

Analytical methods. A HITACHI S-3400 N Type II Scanning electron microscopy (SEM) was used to collect information about materials morphology and size. Micrographs were collected at different magnifications $(500-10 \mathrm{k})$ at a voltage set to $18-20 \mathrm{keV}$ and a working distance set at $4.3 \mathrm{~mm}$. The crystalline composition and structure of the calcium carbonate phases were characterized by X-ray diffraction (XRD, Shimadzu X-ray diffractometer) using $\mathrm{Cu}-\mathrm{Ka}$ radiation at $40 \mathrm{kV}$ and $30 \mathrm{~mA}$. The diffraction pattern in the $10-80^{\circ} 2 \theta$ range was collected at a scanning angle step of $0.02^{\circ}$ and $2 \% \mathrm{~min}^{-1}$ scan speed. Evaluation of diffraction patterns and identification of the carbonates polymorphs present in final materials was performed using the Calcite and Vaterite databases ${ }^{41,43}$.

Raman spectra were acquired using a Renishaw in Via-Raman microscope equipped with a diode laser of $785 \mathrm{~nm}$ (or and $473 \mathrm{~nm}$ ). A beam size of $5 \times, 20 \times, 50 \times$ and $100 \times$ long working distance objectives was used to characterize the materials at the Diamond Light Source. The spectra were recorded at $50 \mathrm{~s}$ or $100 \mathrm{~s}$ acquisition time over the range $100-2000 \mathrm{~cm}^{-1}$.

A Micro Fourier Transform Infrared (FTIR) bench top spectrometer (Nicolet 6700 Thermo equipped with a Smart Orbit ATR and a diamond window) was used to collect infrared spectra Lab at the Diamond Light Source. Vibration frequency changes in carbonates materials were recorded with 64 scans per FTIR absorption spectra in the mid-infrared range from 4000 to $600 \mathrm{~cm}^{-1}$ at a resolution of $2 \mathrm{~cm}^{-1}$. Synthetic standards mixed with boron nitride were also used as FTIR standards. Particle size characterization was performed by NanoSight LM 20 device equipped with a laser beam that is introduced to the sample through a glass prism. Samples were measurement at a controlled temperature of $23^{\circ} \mathrm{C}$, manual camera shutter at 500, screen gain adjustment at 100-150 and a capture duration of $20 \mathrm{~s}$. The samples were advanced between each recording to ensure replicate measurements. The NTA acquisition settings were optimized to track and measured each particle on frame-by-frame. The sample prism was cleaned after each recording video by using Milli-Q water until no visible particles were observed in the viewing windows. The performance of the system was investigated by measuring nanoparticle polystyrene latex microspheres of $400 \mathrm{~nm}$. The BET adsorption measurements at $-196^{\circ} \mathrm{C}$ (in liquid nitrogen) were performed on a NOVA 2200 Quantachrome instrument (Quantachrome Corporation, Boynton Beach, FL, USA). Samples were outgassed under high vacuum at room temperature (according to IUPAC and to ISO 9277) before physisorption measurements, so that physically adsorbed species were removed from the adsorbent surface. A dedicated software of instrument was used for the data fitting within the usual adsorption models (Brunauer-Emmet-Teller (BET) model) for specific area determination. The total pore volume was estimated directly from the nitrogen adsorption-desorption isotherm at relative pressure of $\mathrm{P} / \mathrm{P} 0=0.95$.

Adsorption experiments. Adsorption studies were conducted under dynamic regime assured by a magnetic stirrer at $150 \mathrm{rpm}$. The $\mathrm{pH}$ was measured and maintained constant during the all the adsorption experiments by the potentiometric titrator (SI Analytics7000) set on $\mathrm{pH}$-stat method to keep the $\mathrm{pH}$ constant during the entire adsorption time set at $120 \mathrm{~min}$. The titrator automatically added acid $\mathrm{HCl}(10 \mathrm{mmol} / \mathrm{L})$ during the experiments at $\mathrm{pH} 5$ and 7 and base $\mathrm{NaOH}(10 \mathrm{mmol} / \mathrm{L})$ for the experiment at $\mathrm{pH} 9$, in fine volume steps $(0.01 \mathrm{~mL})$, as required to maintain the $\mathrm{pH}$ constant. Experimental sets were run at $\mathrm{RY} 84$ initial concentration set from 5 to $60 \mathrm{mg} / \mathrm{L}$, pH set from 6 to 11.2 and solid concentration of $1 \mathrm{~g} / \mathrm{L}$. The $3 \mathrm{~mL}$ aliquots were taken at various time intervals, filtered via $0.22 \mu \mathrm{m}$ cellulose nitrate membrane and prepared for RY84 analysis by UV-Vis (Thermo Scientific Microplate reader Multiskan GO with cuvette) at $\Lambda=400 \mathrm{~nm}$. The UV-Vis detection limit for RY84 is $<1 \mathrm{mg} / \mathrm{L}$. Adsorption experiments were run in duplicates. Blanks for $\mathrm{pH}$ and concentration dependent experiments were used to check materials dissolution. Standard deviation of the results was found below $5 \%$.

Photodegradation experiments. Photodegradation experiments in the presence and the absence of $\mathrm{H}_{2} \mathrm{O}_{2}$ were carried out in petri dishes $(40 \mathrm{ml})$ and using a UVA bench lamp at 15 watts, $365 \mathrm{~nm}$ and 115 VAC/60 Hz (Cole-Parmer). Initial concentrations of RY84 were 10, 20 and $40 \mathrm{mg} / \mathrm{L}$ and exposure time was set to $3 \mathrm{~h}$. After $60 \mathrm{~min}$ of equilibration, the adsorbent was removed by filtration using $0.2 \mu \mathrm{m}$ filter and a solution of diluted $30 \% \mathrm{H}_{2} \mathrm{O}_{2}$ was added to achieve the selected $\mathrm{H}_{2} \mathrm{O}_{2}$ concentrations ( 20 and $40 \mathrm{mmol} / \mathrm{L}$ ), these being the basic conditions for experimental tests. Samples of the reaction medium were withdrawn at regular intervals for pollutant absorbance measurement. The kinetic of dye photodegradation in the presence as well as in the absence of $\mathrm{H}_{2} \mathrm{O}_{2}$, beside UVA, was fitted using first order kinetic model.

RY84 uptake from wastewater via adsorption and photodegradation. Adsorption studies were also carried out by using wastewater. They were designed similar to distilled water experiments: room temperature and $150 \mathrm{rpm}$ mixing speed, but only using one dye concentration and adsorbent dose $(1 \mathrm{~g} / \mathrm{L})$. The wastewater was collected from municipal waste water treatment plant (WWTP) and spiked with minor volume of dye 
stock solution to obtain dye concentration of $10 \mathrm{mg} / \mathrm{L}$. The initial $\mathrm{pH}$ of the dye polluted wastewater was 7.5. Photodegradation experiments post adsorption using wastewater were run in a similar manner as the ones run in distilled water. The characterization of wastewater is presented in Table S2.

\section{Data availability}

All data needed to evaluate the conclusion in this paper are presented in the paper.

Received: 21 December 2021; Accepted: 14 February 2022

Published online: 24 February 2022

\section{References}

1. Chen, J. et al. Removal behaviors and mechanisms for series of azo dye wastewater by novel nano constructed macro-architectures material. Biores. Technol. 322, 124556. https://doi.org/10.1016/j.biortech.2020.124556 (2021).

2. Jargalsaikhan, M., Lee, J., Jang, A. \& Jeong, S. Efficient removal of azo dye from wastewater using the non-toxic potassium ferrate oxidation-coagulation process. Appl. Sci. 11, 6825. https://doi.org/10.3390/app11156825 (2021).

3. Karimifard, S. \& Alavi Moghaddam, M. R. Application of response surface methodology in physicochemical removal of dyes from wastewater: A critical review. Sci. Total Environ. 640-641, 772-797. https://doi.org/10.1016/j.scitotenv.2018.05.355 (2018).

4. Uddin, M. J., Ampiaw, R. E. \& Lee, W. Adsorptive removal of dyes from wastewater using a metal-organic framework: A review. Chemosphere 284, 131314. https://doi.org/10.1016/j.chemosphere.2021.131314 (2021).

5. Adel, M., Ahmed, M. A. \& Mohamed, A. A. Effective removal of indigo carmine dye from wastewaters by adsorption onto mesoporous magnesium ferrite nanoparticles. Environ. Nanotechnol. Monitor. Manag. 16, 100550. https://doi.org/10.1016/j.enmm. 2021.100550 (2021).

6. Bal, G. \& Thakur, A. Distinct approaches of removal of dyes from wastewater: A review. Mater. Today Proc. https://doi.org/10. 1016/j.matpr.2021.09.119(2021).

7. Li, X.-L., Zhang, W., Huang, Y.-Q., Wang, Q. \& Yang, J.-M. Superior adsorptive removal of azo dyes from aqueous solution by a Ni(II)-doped metal-organic framework. Colloids Surf. A 619, 126549. https://doi.org/10.1016/j.colsurfa.2021.126549 (2021).

8. Sirajudheen, P., Nikitha, M. R., Karthikeyan, P. \& Meenakshi, S. Perceptive removal of toxic azo dyes from water using magnetic Fe3O4 reinforced graphene oxide-carboxymethyl cellulose recyclable composite: Adsorption investigation of parametric studies and their mechanisms. Surf. Interfaces 21, 100648. https://doi.org/10.1016/j.surfin.2020.100648 (2020).

9. Ghabaee, S., Behin, J., Ansari, M. \& Rajabi, L. Synthesis and characterization maleate-alumoxane nanoparticles for removal of reactive yellow 84 dye from aqueous solution. Adv. Powder Technol. 31, 2061-2071. https://doi.org/10.1016/j.apt.2020.02.040 (2020).

10. Hossain, M. I. et al. Synthesis and characterization of graphene oxide-ammonium ferric sulfate composite for the removal of dyes from tannery wastewater. J. Market. Res. 12, 1715-1727. https://doi.org/10.1016/j.jmrt.2021.03.097 (2021).

11. Moradi, O. \& Sharma, G. Emerging novel polymeric adsorbents for removing dyes from wastewater: A comprehensive review and comparison with other adsorbents. Environ. Res. 201, 111534. https://doi.org/10.1016/j.envres.2021.111534 (2021).

12. Margha, F. H., Radwan, E. K., Badawy, M. I. \& Gad-Allah, T. A. Bi2O3- $\mathrm{BiFeO}_{3}$ glass-ceramic: Controllable beta/gamma-Bi ${ }_{2} \mathrm{O}_{3}$ transformation and application as magnetic solar-driven photocatalyst for water decontamination. ACS Omega 5, 14625-14634. https://doi.org/10.1021/acsomega.0c01307 (2020).

13. Abdel-Karim, A. et al. High-performance mixed-matrix membranes enabled by organically/inorganic modified montmorillonite for the treatment of hazardous textile wastewater. Chem. Eng. J. https://doi.org/10.1016/j.cej.2020.126964 (2021).

14. Neamtu, M. et al. Iron phthalocyanine-sensitized magnetic catalysts for BPA photodegradation. Sci. Rep. 10, 5376. https://doi.org/ 10.1038/s41598-020-61980-6 (2020).

15. Neamtu, M., Nadejde, C., Hodoroaba, V. D., Schneider, R. J. \& Panne, U. Singlet oxygen generation potential of porphyrin-sensitized magnetite nanoparticles: Synthesis, characterization and photocatalytic application. Appl. Catal. B-Environ. 232, 553-561. https:// doi.org/10.1016/j.apcatb.2018.03.079 (2018).

16. Nadeide, C. et al. Hybrid iron-based core-shell magnetic catalysts for fast degradation of bisphenol A in aqueous systems. Chem. Eng. J. 302, 587-594. https://doi.org/10.1016/j.cej.2016.05.090 (2016).

17. Coha, M., Farinelli, G., Tiraferri, A., Minella, M. \& Vione, D. Advanced oxidation processes in the removal of organic substances from produced water: Potential, configurations, and research needs. Chem. Eng. J. https://doi.org/10.1016/j.cej.2021.128668 (2021).

18. Duan, X. G., Sun, H. Q., Shao, Z. P. \& Wang, S. B. Nonradical reactions in environmental remediation processes: Uncertainty and challenges. Appl. Catal. B-Environ. 224, 973-982. https://doi.org/10.1016/j.apcatb.2017.11.051 (2018).

19. Banihashemi, A., Zare, K., Javanbakht, V. \& Mohammadifard, H. Calcium carbonate nanoparticles fabricated by a facile method based on the colloidal gas aphrons for removal of fluoride ions from aqueous solutions. Mater. Chem. Phys. 258, 123934. https:// doi.org/10.1016/j.matchemphys.2020.123934 (2021).

20. Bouteraa, S., Saiah, F. B. D., Hamouda, S. \& Bettahar, N. Zn-M-CO layered double hydroxides $(\mathrm{M}=\mathrm{Fe}, \mathrm{Cr}$, or $\mathrm{Al})$ : Synthesis, characterization, and removal of aqueous indigo carmine. Bull. Chem. React. Eng. Catal. 15, 43-54. https://doi.org/10.9767/bcrec. 15.1.5053.43-54 (2020).

21. Azari, A. et al. Experimental design, modeling and mechanism of cationic dyes biosorption on to magnetic chitosan-lutaraldehyde composite. Int. J. Biol. Macromol. 131, 633-645. https://doi.org/10.1016/j.ijbiomac.2019.03.058 (2019).

22. Tobler, D. J., Rodriguez Blanco, J. D., Sørensen, H. O., Stipp, S. L. S. \& Dideriksen, K. Effect of pH on amorphous calcium carbonate structure and transformation. Cryst. Growth Des. https://doi.org/10.1021/acs.cgd.6b00630 (2016).

23. Bots, P., Benning, L. G., Rodriguez-Blanco, J.-D., Roncal-Herrero, T. \& Shaw, S. Mechanistic insights into the crystallization of amorphous calcium carbonate (ACC). Cryst. Growth Des. 12, 3806-3814 (2012).

24. Rodriguez-Blanco, J. D., Shaw, S. \& Benning, L. G. The kinetics and mechanisms of amorphous calcium carbonate (ACC) crystallization to calcite, via vaterite. Nanoscale 3, 265-271. https://doi.org/10.1039/c0nr00589d (2011).

25. Rodriguez-Blanco, J., Shaw, S. \& Benning, L. How to make 'stable'ACC: Protocol and preliminary structural characterization. Mineral. Mag. 72, 283-286 (2008).

26. Cartwright, J. H. E., Checa, A. G., Gale, J. D., Gebauer, D. \& Sainz-Diaz, C. I. Calcium carbonate polyamorphism and its role in biomineralization: How many amorphous calcium carbonates are there?. Angew. Chem. Int. Ed. 51, 11960-11970. https://doi.org/ 10.1002/anie.201203125 (2012).

27. Gebauer, D. et al. Proto-calcite and proto-vaterite in amorphous calcium carbonates. Angew. Chem. Int. Ed. 49, 8889-8891. https:// doi.org/10.1002/anie.201003220(2010).

28. Hodson, M. E. et al. Biomineralisation by earthworms: An investigation into the stability and distribution of amorphous calcium carbonate. Geochem. Trans. https://doi.org/10.1186/s12932-015-0019-z (2015).

29. Tobler, D. J. et al. Citrate effects on amorphous calcium carbonate (acc) structure, stability, and crystallization. Adv. Func. Mater. 25, 3081-3090. https://doi.org/10.1002/adfm.201500400 (2015). 
30. Collivignarelli, M. C., Abba, A., Miino, M. C. \& Damiani, S. Treatments for color removal from wastewater: State of the art. J. Environ. Manage. 236, 727-745. https://doi.org/10.1016/j.jenvman.2018.11.094 (2019).

31. Klamerth, N., Malato, S., Aguera, A. \& Fernandez-Alba, A. Photo-Fenton and modified photo-Fenton at neutral pH for the treatment of emerging contaminants in wastewater treatment plant effluents: A comparison. Water Res. 47, 833-840 (2013).

32. Fernandez, C., Larrechi, M. S. \& Callao, M. P. An analytical overview of processes for removing organic dyes from wastewater effluents. Trac-Trends Anal. Chem. 29, 1202-1211. https://doi.org/10.1016/j.trac.2010.07.011 (2010).

33. Chandrabose, G. et al. Removal and degradation of mixed dye pollutants by integrated adsorption-photocatalysis technique using 2-D MoS2/TiO2 nanocomposite. Chemosphere 279, 130467. https://doi.org/10.1016/j.chemosphere.2021.130467 (2021).

34. Huang, Y. et al. Degradation of contaminants of emerging concern by $\mathrm{UV} / \mathrm{H} 2 \mathrm{O} 2$ for water reuse: Kinetics, mechanisms, and cytotoxicity analysis. Water Res. 174, 115587. https://doi.org/10.1016/j.watres.2020.115587 (2020).

35. Neamtu, M., Siminiceanu, I., Yediler, A. \& Kettrup, A. Kinetics of decolorization and mineralization of reactive azo dyes in aqueous solution by the UV/H2O2 oxidation. Dyes Pigm. 53, 93-99. https://doi.org/10.1016/s0143-7208(02)00012-8 (2002).

36. Neamtu, M., Yediler, A., Siminiceanu, I. \& Kettrup, A. Oxidation of commercial reactive azo dye aqueous solutions by the photoFenton and Fenton-like processes. J. Photochem. Photobiol. A 161, 87-93. https://doi.org/10.1016/s1010-6030(03)00270-3 (2003).

37. Nguyen, C. H. \& Juang, R.-S. Efficient removal of cationic dyes from water by a combined adsorption-photocatalysis process using platinum-doped titanate nanomaterials. J. Taiwan Inst. Chem. Eng. 99, 166-179. https://doi.org/10.1016/j.jtice.2019.03.017 (2019).

38. Nguyen, C. H., Tran, M. L., Tran, T. T. V. \& Juang, R.-S. Enhanced removal of various dyes from aqueous solutions by UV and simulated solar photocatalysis over $\mathrm{TiO}^{2} / \mathrm{ZnO} / \mathrm{rGO}$ composites. Sep. Purif. Technol. 232, 115962. https://doi.org/10.1016/j.seppur. 2019.115962 (2020).

39. Upadhyay, G. K., Rajput, J. K., Pathak, T. K., Pal, P. K. \& Purohit, L. P. Tailoring and optimization of hybrid $\mathrm{ZnO}_{\mathrm{TiO}}$ :CdO nanomaterials for advance oxidation process under visible light. Appl. Surf. Sci. 509, 145326. https://doi.org/10.1016/j.apsusc.2020. $145326(2020)$

40. Wang, Y., Moo, Y. X., Chen, C., Gunawan, P. \& Xu, R. Fast precipitation of uniform $\mathrm{CaCO}_{3}$ nanospheres and their transformation to hollow hydroxyapatite nanospheres. J. Colloid Interface Sci. 352, 393-400. https://doi.org/10.1016/j.jcis.2010.08.060 (2010).

41. Lafuente, B., Downs, R. T., Yang, H. \& Stone, N. The power of databases: the RRUFF project. In: Highlights in Mineralogical Crystallography, T Armbruster and R M Danisi, eds. Berlin, Germany, W. De Gruyter, pp 1-30. (2015).

42. Anthony, J. W., Bideaux, R. A., Bladh, K. W. \& Nichols, M. C. Handbook of Mineralogy. (Mineral Data Publishing, Tucson Arizona, USA, by permission of the Mineralogical Society of America., 1990).

43. Downs, R. T., Bartelmehs, K. L., Gibbs, G. V. \& Boisen, M. B. Interactive software for calculating and displaying X-ray or neutron powder diffractometer patterns of crystalline materials. Am. Miner. 78, 1104-1107 (1993).

44. DeCarlo, T. M. Characterizing coral skeleton mineralogy with Raman spectroscopy. Nat. Commun. 9, 5325. https://doi.org/10. 1038/s41467-018-07601-3 (2018).

45. Wehrmeister, U., Soldati, A. L., Jacob, D. E., Häger, T. \& Hofmeister, W. Raman spectroscopy of synthetic, geological and biological vaterite: A Raman spectroscopic study. J. Raman Spectrosc. 41, 193-201. https://doi.org/10.1002/jrs.2438 (2010).

46. Trushina, D. B., Bukreeva, T. V., Kovalchuk, M. V. \& Antipina, M. N. CaCO(3) vaterite microparticles for biomedical and personal care applications. Mater. Sci. Eng. C Mater. Biol. Appl. 45, 644-658. https://doi.org/10.1016/j.msec.2014.04.050 (2014).

47. Wei, H., Shen, Q., Zhao, Y., Wang, D.-J. \& Xu, D.-F. Influence of polyvinylpyrrolidone on the precipitation of calcium carbonate and on the transformation of vaterite to calcite. J. Cryst. Growth 250, 516-524. https://doi.org/10.1016/s0022-0248(02)02484-3 (2003).

48. Buzgar, N. \& Apopei, A. I. The Raman study of certain carbonates. Geol. Tomul. LV 2, 97-112 (2009).

49. Donnelly, F. C. et al. Synthesis of $\mathrm{CaCO} 3$ nano- and micro-particles by dry ice carbonation. Chem. Commun. 53, 6657-6660. https://doi.org/10.1039/c7cc01420a (2017).

50. Vagenas, N., Gatsouli, A. \& Kontoyannis, C. G. Quantitative analysis of synthetic calcium carbonate polymorphs using FT-IR spectroscopy. Talanta 59, 831-836. https://doi.org/10.1016/s0039-9140(02)00638-0 (2003).

51. Zhang, Z., Xie, Y., Xu, X., Pan, H. \& Tang, R. Transformation of amorphous calcium carbonate into aragonite. J. Cryst. Growth 343, 62-67. https://doi.org/10.1016/j.jcrysgro.2012.01.025 (2012).

52. Saraya, M.E.-S.I. \& Rokbaa, H. H. A. L. Preparation of vaterite calcium carbonate in the form of spherical nano-size particles with the aid of polycarboxylate superplasticizer as a capping agent. Am. J. Nanomater. 4, 44-51. https://doi.org/10.12691/ajn-4-2-3 (2016).

53. Carr, B. et al. Applications of nanoparticle tracking analysis in nanoparticle research: A mini review. Eur. J. Parent. Pharm. Sci. 14, 45-50 (2009).

54. Thommes, M. et al. Physisorption of gases, with special reference to the evaluation of surface area and pore size distribution (IUPAC Technical Report). Pure Appl. Chem. 87, 1051-1069. https://doi.org/10.1515/pac-2014-1117 (2015).

55. Somasundaran, P. \& Agar, G. E. The zero point of charge of calcite. J. Colloid Interface Sci. 24, 433-440. https://doi.org/10.1016/ 0021-9797(67)90241-X (1967).

56. Al Mahrouqi, D., Vinogradov, J. \& Jackson, M. D. Zeta potential of artificial and natural calcite in aqueous solution. Adv. Colloid Interface Sci. 240, 60-76. https://doi.org/10.1016/j.cis.2016.12.006 (2017).

57. El Malah, T. et al. A bipyridinium-based polyhydrazone adsorbent that exhibits ultrahigh adsorption capacity for the anionic azo dye, direct blue 71. Chem. Eng. J. 409, 128195. https://doi.org/10.1016/j.cej.2020.128195 (2021).

58. Abdel Ghafar, H. H., Radwan, E. K. \& El-Wakeel, S. T. Removal of Hazardous Contaminants from Water by Natural and Zwitterionic Surfactant-modified Clay. ACS Omega 5, 6834-6845. https://doi.org/10.1021/acsomega.0c00166 (2020).

59. Qiu, H. et al. Critical review in adsorption kinetic models. J. Zhejiang Univ. Sci. A 10, 716-724. https://doi.org/10.1631/jzus.A0820 524 (2009).

60. Sparks, L. D. Soil Physical Chemistry 136-182 (Boca Raton CRC Press, 1999).

61. Ho, Y.-S. Review of second-order models for adsorption systems. J. Hazard. Mater. 136, 681-689. https://doi.org/10.1016/j.jhazm at.2005.12.043 (2006).

62. Simonin, J.-P. On the comparison of pseudo-first order and pseudo-second order rate laws in the modeling of adsorption kinetics. Chem. Eng. J. 300, 254-263. https://doi.org/10.1016/j.cej.2016.04.079 (2016).

63. Al-Ghouti, M. A. \& Da'ana, D. A. Guidelines for the use and interpretation of adsorption isotherm models: A review. J. Hazard. Mater. 393, 22. https://doi.org/10.1016/j.jhazmat.2020.122383 (2020).

64. Ayawei, N., Ebelegi, A. N. \& Wankasi, D. Modelling and interpretation of adsorption isotherms. J. Chem. 2017, 3039817. https:// doi.org/10.1155/2017/3039817 (2017).

65. Azari, A., Nabizadeh, R., Nasseri, S., Mahvi, A. H. \& Mesdaghinia, A. R. Comprehensive systematic review and meta-analysis of dyes adsorption by carbon-based adsorbent materials: Classification and analysis of last decade studies. Chemosphere 250, 126238. https://doi.org/10.1016/j.chemosphere.2020.126238 (2020).

66. El Haddad, M. et al. Adsorptive removal of reactive yellow 84 dye from aqueous solutions onto animal bone meal. J. Mater. Environ. Sci. 3, 1019-1026 (2012).

67. Barka, N., Qourzal, S., Assabbane, A., Nounah, A. \& Ait-Ichou, Y. Removal of Reactive Yellow 84 from aqueous solutions by adsorption onto hydroxyapatite. J. Saudi Chem. Soc. https://doi.org/10.1016/j.jscs.2010.10.002 (2011). 
68. Abdolmohammad-Zadeh, H., Ghorbani, E. \& Talleb, Z. Zinc-aluminum layered double hydroxide as a nano-sorbent for removal of reactive yellow 84 dye from textile wastewater effluents. J. Iran. Chem. Soc. 10, 1103-1112. https://doi.org/10.1007/s13738-0130255-z (2013).

69. Filipkowska, U. \& Jóźwiak, T. Application of chemically-cross-linked chitosan for the removal of reactive black 5 and reactive yellow 84 dyes from aqueous solutions. J. Polym. Eng. 33, 735-747. https://doi.org/10.1515/polyeng-2013-0166 (2013).

70. Rache, M. L. et al. Azo-dye orange II degradation by the heterogeneous Fenton-like process using a zeolite Y-Fe catalyst-Kinetics with a model based on the Fermi's equation. Appl. Catal. B-Environ. 146, 192-200. https://doi.org/10.1016/j.apcatb.2013.04.028 (2014).

71. Pintar, A. \& Levec, J. Catalytic-oxidation of organics in aqueous-solutions:1-kinetics of phenol oxidation. J. Catal. 135, 345-357. https://doi.org/10.1016/0021-9517(92)90038-j (1992).

72. Neamtu, M. \& Frimmel, F. Photodegradation of endocrine disrupting chemical nonylphenol by simulated solar UV-irradiation. Sci. Total Environ. 369, 295-306. https://doi.org/10.1016/j.scitotenv.2006.05.002 (2006).

73. Rueda-Marquez, J. J., Levchuk, I., Ibanez, P. F. \& Sillanpaa, M. A critical review on application of photocatalysis for toxicity reduction of real wastewaters. J. Clean. Prod. https://doi.org/10.1016/j.jclepro.2020.120694 (2020).

74. Zhao, M. et al. Preparation of core-shell structured $\mathrm{CaCO}_{3}$ microspheres as rapid and recyclable adsorbent for anionic dyes. $R$. Soc. Open Sci. 4, 170697. https://doi.org/10.1098/rsos.170697 (2017).

\section{Acknowledgements}

Authors acknowledge to Dr. eng. Cristina Coromelci and Dr. Georgiana Bulai for help with BET and XRD measurements, respectively. Spectroscopic nanoparticles characterization was carried out using peripheral laboratory facilities at the Diamond Light Source, UK, that is acknowledged for allowing access to L. B.

\section{Author contributions}

L.B. Initiated this research, nanoparticles syntheses, spectroscopic measurements and supervised the adsorption experiments. M.N. supervised and conceptualized the photodegradation experiments. A.E.M. carried out nanoparticle syntheses, NTA, Raman, FTIR and XRD data interpretation, the adsorption and photodegradation experiments. S. T. performed the SEM measurements, whereas F. B. the NTA measurements. L.B., A.E.M and M.N. wrote this paper.

\section{Competing interests}

The authors declare no competing interests.

\section{Additional information}

Supplementary Information The online version contains supplementary material available at https://doi.org/ 10.1038/s41598-022-07134-2.

Correspondence and requests for materials should be addressed to L.B. or M.N.

Reprints and permissions information is available at www.nature.com/reprints.

Publisher's note Springer Nature remains neutral with regard to jurisdictional claims in published maps and institutional affiliations.

Open Access This article is licensed under a Creative Commons Attribution 4.0 International License, which permits use, sharing, adaptation, distribution and reproduction in any medium or format, as long as you give appropriate credit to the original author(s) and the source, provide a link to the Creative Commons licence, and indicate if changes were made. The images or other third party material in this article are included in the article's Creative Commons licence, unless indicated otherwise in a credit line to the material. If material is not included in the article's Creative Commons licence and your intended use is not permitted by statutory regulation or exceeds the permitted use, you will need to obtain permission directly from the copyright holder. To view a copy of this licence, visit http://creativecommons.org/licenses/by/4.0/.

(c) The Author(s) 2022 